\title{
Obesity, Poverty and Income Inequality in USA: Evidence from Panel Cointegration and Mixed Model Methodology
}

\author{
Tahereh Alavi Hojjat \\ DeSales University \\ Monir Uddin Ahmed \\ Shahjalal University of Science and Technology
}

Over the past several decades, obesity has grown into a major global epidemic. Obesity in the United States is widely acknowledged to be a severe and growing problem. In this paper, economic costs of obesity are discussed with an emphasis on healthcare costs, as obesity is perhaps among the largest contributing factor to high costs of health care in America. Stemming the obesity epidemic cannot be separated from stemming the tide of poverty and income inequality gap. In this study, we used panelcointegration test using data from 1998-2012 and our results suggests that there is a long-run relationship among obesity, inequality and poverty.

\section{INTRODUCTION}

Over the past several decades, obesity has grown to be a major global epidemic. In the United States (U.S.), the rate of obesity has doubled since 1970 to over 30 percent, with more than two-thirds of Americans now overweight (Hammond and Levine, 2010). Obesity is not only the rise among young adults but also throughout the older population as well (Hojjat \& Hojjat, 2017). In 2009, nearly one in eight Americans (12.6\%) was aged 65 or older. The ratio is expected to jump to one in five (19.7\%) by 2030, due in part to longer life expectancies and the aging of baby boomer generation. Because the higher rates of obesity are found among baby boomers, aged 44-62 in 2008, it is likely that the prevalence of obesity among older will continue to climb in the coming decades. The study anticipated that by 2010 , $37.4 \%$ of adults ages 65 and older will be obese and if this trajectory continue unabated, it is project that nearly half of elderly population will be obese in 2030 (Sommers, 2009).

In 2010, no state had a prevalence of obesity of less than 20 percent. Thirty-six states had a 25 percent or more; 12 of these states (Alabama, Arkansas, Kentucky, Louisiana, Michigan, Mississippi, Missouri, Oklahoma, South Carolina, Tennessee, Texas, and West Virginia) had a 30 percent or more.

Obesity is not limited to the United States; most of the world has grown fatter since the 1970s. According to the most recent figures from the National Child Measurement Program, which assesses the height and weight of primary children in England, just over 33 percent of 11-year-olds are now overweight or obese and among four- and five-year-olds it is 22 percent. The figures are similar in Wales, Scotland, and Northern Ireland (Winterman, 2012). As the median person becomes fatter, it becomes socially acceptable to be fat (Jenkins, 2013). 
Hammond and Levine (2010) estimated annual medical cost of obesity in the United States may be as much as $100 \%$ higher than for healthy weight adults, and nationwide "excess" medical spending may amount to as much as $\$ 147$ billion annually for adults and $\$ 14.3$ billion annually for children.

Causes and consequences of this are beyond the scope of this paper, as it can be very complex regarding heterogeneous population at the individual level. Therefore, we will analyze the issue from an economic point of view; considering the major factors contributing to obesity in general.

The first part of this article provides a brief review of literature. Section 2 demonstrate an economic analysis of the obesity with emphasize on role of government and technology in price of food and hence consumption of different types of foods. Section 3 analyzes the relationship of poverty and obesity. Section 4 describes the consequences of obesity. In Section 5 we give an overview of food policy recommendation to fight against obesity and finally, section 6 concludes the paper.

The terms "overweight" and "obesity" are used to express weight ranges that are greater than what is considered healthy for a given height. In the case of adults, weight and height are used to calculate "Body Mass Index" (BMI) to define what qualifies as overweight and obese. Obesity in adults is generally defined as a BMI of 30 or greater, with a BMI of 25-29 categorized as being overweight (Dalrymple, 2010), for more details, see Table 1 on weight range. According to the National Health and Nutrition Examination Survey (NHANES), obesity prevalence in 2007-2008 was 32.2 percent and 35.5 percent among adult males and females, representing a more than 100 percent increase from 1976-1980 and a 50 percent increase from 1988-1994 (Flegal et al., 2010).

Obesity is not only on the rise among young adults, but also throughout the older population as well. In 2009, nearly one in eight Americans (12.6 percent) was age 65 or older. This ratio is expected to jump to one in five (19.7 percent) by 2030 , due in part to longer life expectancies and the aging of the baby boom generation. Because the highest rates of obesity are found among baby boomers, aged 44-62 in 2008 , it is likely that the prevalence of obesity among older adults will continue to climb in the coming decades as this population ages. By 2010, 37.4 percent of adults aged 65 and older are anticipated to be obese. If this trajectory continues unabated, it is projected that nearly half of the elderly population will be obese in 2030 (Sommers, 2009).

The nation is spending $\$ 75$ billion a year on weight-related diseases such as; type II diabetes, heart disease, hypertension, high cholesterol, gallbladder disease, and osteoarthritis as merely on the top of the list. Almost 80 percent of obese adults have one of these conditions, and nearly 40 percent have two or more. Authorities view obesity as one of the most serious public health problem of the 21 st century (Barness et al., 2007). A scary warning comes from the United States, where obesity is considered a real pandemic, in addition to adults; it already involves about nine million young people (Sturm, 2007).

At present, obesity is not only a problem from the clinical point of view; it is also a social issue of considerable importance. We are going to review different phases of obesity since 1970s: Phase 1 of obesity began in the early 1970s and is ongoing: average weight is progressively increasing among children from all socioeconomic levels, racial and ethnic groups, and regions of the country. Today, about one in three children and adolescents is overweight (with a BMI in the 85th to 95th percentile for age and sex) or obese (BMI above the 95th percentile), and the proportion approaches one in two in certain minority groups. Though it has attracted much attention from the medical profession and the public, childhood obesity during this phase has actually had little effect on public health, because obese child may remain relatively healthy for years. Phase 2 of obesity is characterized by the emergence of serious weight-related problems (Ludwig, 2007). The incidence of Type 2 diabetes among adolescents, though still not high, has increased by a factor of more than 10 in the past two decades and may now exceed that of Type 1 diabetes among black and Hispanic adolescents. A fatty liver associated with excessive weight, unrecognized in the pediatric literature before 1980, today occurs in about one in three obese children. Other obesity-related complications affecting virtually every organ - ranging from crippling orthopedic problems to sleep apnea - are being diagnosed with increasing frequency in children. There is also a heavy psychosocial toll: obese children tend to be socially isolated and have high rates of disordered eating, anxiety, and depression. When they reach adulthood, they are less likely than their thinner counterparts to complete college and are more likely to live in poverty. 
It may take many years to reach phase 3 of the epidemic, in which the medical complications of obesity lead to life-threatening disease. Poverty and social isolation would complicate the timely identification and management of such problems. Shockingly, the risk of dying by middle age is already two to three times as high among obese adolescent girls as it is among those of normal weight, even after other lifestyle factors are taken into account (Ludwig, 2007).

Obesity is implicated in 300,000 premature deaths per year in the United States, which is somewhat less than the number associated with tobacco use, but substantially more than the numbers associated with alcohol and illicit drug use (Chou et al., 2004). In addition to physical ailments, obesity has been found to be related to lower satisfaction with work, family relations, partner relationships, social activities, and depression (Stutzer, 2007).

\section{REVIEW OF LITERATURE}

There has been an increase in the prevalence of obesity amongst both genders of all ages and ethnic and racial backgrounds. According to the National Association of School Nurses, obesity has more than tripled among adolescents in the past 20 years, and 33 percent of students today are obese or overweight, with related mental and physical health issues, including depression and the growing number of Type 2 diabetes cases (Table 2).

Published scientific research suggests that obesity is caused by the following: excessive consumption of protein, starch, sugar, and fat; by calories and non-calorie sweeteners; by meals and by snacks; by beverages and by solid foods; by eating in fast-food and in full-service restaurants, as well as by eating at home. The only food that has not been linked to obesity is vegetables and fruits (Rolls et al., 2004).

Energy-dense foods and energy-dense diets have been blamed for the global obesity epidemic (French et al., 2001). Energy density of food is defined as the energy per unit weight or volume ( $\mathrm{kcal} / 100 \mathrm{~g}$ or megajoules per kilogram). The frequency of consuming restaurant food was positively associated with increased body fatness in adults. The increasing proportion of household food income spent on food prepared away from home in the United States may therefore help explain the rising national prevalence of obesity (McCrory et al., 1999), snacks, sweets, and desserts (Zizza et al., 2001), sweetened soft drinks (Bray et al., 2004) and large portions sizes (Rolls et al., 2002) have all been linked to greater obesity risk.

As Americans debate what is most to blame for the nation's obesity epidemic, researchers say they have the strongest evidence yet that sugary drinks play a leading role and that eliminating them would, more than any other single step, make a huge difference (Science Daily). Three studies published in the New England Journal of Medicine represent the most rigorous effort yet to see if there is a link between sugar-sweetened beverages and expanding U.S. waistlines (Brody, 2012). "I know of no other category of food whose elimination can produce weight loss in such a short period of time," said David Ludwig, director of the New Balance Foundation Obesity Prevention Center at Boston Children's Hospital, who led one of the studies. "The most effective single target for an intervention aimed at reducing obesity is sugary beverages" (Ludwig, 2007).

Many observational studies by Gary Beuchamp, Barbara Rolls, and Brian Wansink have linked consumption of sugar-sweetened beverages to weight gain in children and to weight gain and Type 2 diabetes in adults (Brody, 2012). The new research goes well beyond those findings. In one study among women followed for four years, consuming one or more of these drinks per day nearly doubled the risk of developing Type 2 diabetes, compared with women who drank less than one a month. Also "increased energy drinks' calories, may even induce hunger and food intake" (Brody, 2012).

In addition, food choices are made on the basis of taste, cost, convenience, and, to a lesser extent, health and variety (Glanz et al., 1998). Variety refers to the innate drive to secure a varied diet, whereas health refers to concerns with nutrition, chronic disease, and body weight.

The authors used a national sample of 2,967 adults. Response rates were 71 percent to the first survey and 77 percent to the second survey (which was sent to people who completed the first survey). Univariate analyses were used to describe importance ratings. Respondents reported that taste is the most important influence on their food choices, followed by cost. Their results suggest that nutritional concerns 
are less relevance to most people than taste and cost. One implication is that nutrition education programs should attempt to design to promote nutritious diets as being tasty and inexpensive.

Researchers at the U.S. Department of Agriculture (USDA) have pointed out that the American diet is inconsistent with the Food Guide Pyramid (Frazao \& Allshouse, 2003). The consumption of fat and sweets at the Pyramid's tip far exceeds recommendations compared with the low intake of fruits and green leafy vegetables. The reasons that fats and sweets have come to dominate food supply is they are inexpensive, good tasting, energy dense, and convenient to use. Studies support that limited financial resources may be one reason why people are not eating more healthy food (Darmon et al., 2002). These add considerable support to the idea that economic constraints are a major factor in determining the nutritional value of foods purchased. The greater the economic constraints on individuals, the poorer the nutritional quality of foods selected.

The basic idea related to the obesity infrastructure is that "the root of the [obesity] problem lies in the powerful social and cultural forces that promote an energy-rich diet and a sedentary lifestyle" (Brownell $\&$ Horgen, 2004). This environment has intensified over the past thirty years by opening more fast food restaurants and more advertising. The authors explore the economics of food and make it clear that the profit motive of the food industry is not consistent with the current nutritional needs of the nation. Simply stated, increased food consumption means increased profits-but increased food consumption is not consistent with the health needs of our over nourished population. The authors expose the role of corporations that sell foods that contribute to the obesity epidemic. Brownell and Horgan (2004) warn that "American children may be the first generation in modern history to live shorter lives than their parents".

Health economists have demonstrated that the prevalence of obesity is directly proportional to food prices and access to restaurants (Chou et al., 2004). They estimated the effects of fast-food restaurants advertising on children and adolescent being overweight. Their results indicate that a ban on theses advertisements would reduce the number of overweight children ages of 3-11 in a fixed population by 18 percent and would reduce the number of overweight adolescents' ages of 12-18 by 14 percent (Chou et al., 2008). Causes range from a lack of education about food, limited cooking skills, and limited money to buy healthier food to longer working hours and marketing campaigns for junk food aimed at kids (Winterman, 2012).

Although the dramatic rise in obesity can only be explained by environmental factors, there has been little emphasis on the obese persons' economic environment. In particular there has been little research on diet quality and economics of food choice. The broader problem may lie with growing disparities in incomes and wealth, declining value of the minimum wage, food imports, tariffs, and trade. Evidence is emerging that obesity in America is a largely economic issue (Drewnowski \& Darmon, 2005). Jobs have become less strenuous and people must pay a high price for exercise. Calories have become relatively cheaper and exercise has become relatively more expensive.

Rising obesity rates reflect an increasing unequal distribution of income and wealth. It is by now widely accepted that income poverty is a risk factor for premature mortality and increased morbidity (Subramanian \& Kawachi, 2004). Obesity affects poor children disproportionately. Twenty percent of low-income children are obese, compared with about 12 percent of children from more affluent families (Centers for Disease Control and Prevention, 2012). Among girls, race is also an important factor. About 25 percent of black girls are obese, compared with 15 percent of white girls (Ibid). There is in fact intriguing evidence that a person's socioeconomic position can affect health. Braveman (2006) insists that illness is caused by the power imbalance in the capitalist society. We must counteract the free market with social programs.

According to Fineberg, former dean of the Harvard School of Public Health, "a school of public health is like a school of justice." Income inequality affects health by undermining civil society. Lack of social cohesion leads to lower participation in political activity (such as voting, serving in local government, volunteering for political campaign). And lower participation, in turn, reduces government spending on public goods, such as education, and social safety nets (Satel \& Marmor, 2001). It is not just income dispersion itself that matters for health but the proportion of the population that suffers true 
poverty-related problems, such as under-nourishment, lack of access to timey medical care, and so on. In the United Sates, for example, poverty level is higher than in the northern Europe, where the social safety net has much finer mesh. The stunted longevity of poorer people pulls down the average life expectancy for the United States.

Choice of certain products and eating habits are closely related to preferences, lifestyle, culture, ethnicity, and income level. Since World War II, food tradition and culture of the industrialized countries have suffered a sudden and profound change: of course, economic development has led to greater availability and variety of food, but such availability resulted into greater obesity and diseases associated with it (Neel, 1962). In developing countries the food culture is changing, they tend to adopt eating habits similar to those of the western world, and they are particularly influenced by the industrialized American diet and availability of information and access to packaged food. In 1989, Sobel and Stunkard published a seminal review of literature on the relation between socioeconomic status (SES) and obesity. These authors covered the 1960s through the mid-1980s and found 144 published studies on the SES-obesity relation in men, women, and children in the developed and developing world. They found a consistently inverse association for women in developed societies with a higher likelihood of obesity among women in lower socioeconomic status. In developing societies, a strong direct relation was observed for women, men, and children, with a higher likelihood of obesity among persons in higher socioeconomic strata.

The objective of this paper is to review the impacts of socioeconomic status such as education and poverty on obesity (e.g., body mass index, body weight, and overweight).

\section{ECONOMIC ANALYSIS}

This analysis is consistent with behavioral economics, the branch of economics that combines insight from economics, psychology, and neuroscience to better understand consumers' situations in which actual choice behavior deviates from the predications made by earlier theories, which incorrectly concluded that people were always rational, deliberate, and uninfluenced by emotions. Given the utility maximizing rule, the consumer allocates his or her income so that the last dollar spent on each product yields the same amount of extra utility. The rational consumer must compare the extra utility from each product with its added cost (that is, its price). Obesity is the result of individual decisions to choose poor diets and poor life-behavior patterns (including exercise). Unlike in the rational obesity model, these are not decisions of rational economic men or women. The obese person evaluating the long-term expected benefits and costs associated with his or her diet and exercise pattern and choose a combination that leads to obesity. If these benefits and costs were to change, it would be expected that the individual would change his or her diet and exercise pattern accordingly. These expected benefits and costs might change because of changes in external conditions or changes in the individual's preferences.

Technological advancement has led to lower food (or calorie consumption) prices and higher exercise (or calorie expenditure) prices. First, the relative price changes for different types of food have been quite different. Although the price of food relative to other goods has declined by 16 percent since 1960, the prices of fresh fruits and vegetables, fish, and dairy products have increased relatively since 1983 (Finkelstein \& Zuckerman, 2008). Analyses of price increases during the period of 1985-2000 for food in different categories shows that cost of sweets, fats, and caloric beverages fell substantially in relation to fresh vegetables and fruits (Economic Research Service of the USDA, n.d.). Retail price of fresh fruit and vegetables increased 120 percent while price of fats and oils increased by 38 percent from 1985-2000 (Ibid). In February of 2013, the CPI for all fresh vegetable rose 6.3 percent over the previous year. If anything, these trends accentuate income-based disparities in the access to healthy diets. The indices were constructed so they would each equal 100 during the 1982-84 base period. Over the course of 27 years, the fresh fruits and vegetables index rose 49 percent. By contrast, the price index for cakes, cupcakes, and cookies increased until the early 1990s, and then decreased, leaving it 6 percent higher in 2006 than in 1980. In 2006, the fresh fruits and vegetables index stood 40 percent higher than the index for cakes, 
cupcakes, and cookies. The graph suggests that prices for healthy fresh fruits and vegetables are diverging from those for less healthy cakes, cupcakes, and cookies.

The government has poured billions of dollars into dietary campaigns. Agricultural subsidies undercut those efforts by skewing the market in favor of unhealthful calories. Much of the food we have to choose from and how much it costs is determined by Conservation and Energy Act of 2008, known as the "Farm Bill." Federal support for agriculture began during the Great Depression, as a temporary support to farmers, paying them extra when crop prices were low. Nearly eight decades later the benefits flow primarily to large commodity producers of corn and soy, which are as profitable as ever. The current bill gives some $\$ 4.9$ billion a year in automatic payments to growers of such commodity crops, thus driving down prices of corn, corn-based products and corn-fed meats.

Cheap corn has also become a staple in highly processed foods from sweetened breakfast cereals to soft drinks. Between 1985 and 2010 the price of beverages sweetened with high-fructose corn syrup dropped 24 percent, and by 2006 American children consumed an extra 130 calories a day from those beverages (Ibid). Over the same period, the price of fresh fruits and vegetables rose 39 percent. For families on a budget, the price difference can be decisive in their food choices. Thus, the evidence supports the view that it is the relative decline in price of unhealthy foods, not food in general, that has contributed to obesity (Tomer, 2011).

The key factors contributing to lowering food prices in general are technological changes and government subsidies. Thus the lower the cost of calorie intake and the higher the costs of burning calories via exercise are important factors of obesity. Consider the influences deriving from food suppliers, in particular the agricultural, food processing, food distribution, and food preparation industries, especially the food processors and food preparers. There is a great deal of evidence that they are increasingly selling unhealthy foods; foods high in bad fats, sugar and sugary items, processed food, and junk food. Healthy foods in contrast are whole, unprocessed foods, full of fiber, antioxidants, vitamins, minerals, phytonutrients, and healthy fats (Hyman, 2006).

A USDA study showed that low-income households spent approximately $\$ 1.43$ less per person per week on healthy food such as fruit and vegetables compared with higher income households (Blisard et al., 2004). While higher income households did increase fruit and vegetable consumption after an increase in income, lower income household did not. One explanation can be that fruits and vegetables were not a priority among low-income families and that they chose to spend their limited resources on items that were perceived a more essential such as meat, clothing, or rent.

In general, healthier diets cost more. Developments in agriculture and food technology have made added sugars and vegetable oils accessible globally at remarkable low costs. As a result of added fats, the cost of the daily diet has been maintained at a lower level. Americans have the lowest cost food supply in the world. The typical American diet derives almost 40 percent of daily energy from added sugars and from added fats which are relatively inexpensive (Frazoa \& Allshouse, 2003). Given low price and tasty low quality food, marginal utility per dollar of low quality food can be high and that can lead to higher consumption. Diet quality is influenced by socioeconomic position and may well be limited by financial access to nutrient-dense foods.

Considering globally, Americans have the lowest-cost food supply in the world and spend the lowest proportion of disposable income on food. The typical American devotes about 7 percent of his or her spending to food, but the average Indonesian, devotes 43 percent of his or her spending to food (Table 2). People with lower incomes continue to spend much more on food in percentage terms than those with higher incomes. Food accounted for 16.1 percent of spending by consumers with the lowest incomes, according to the Labor Department. Consumers with the highest incomes devoted only 11.6 percent of their spending to food. With the spread of fast food restaurants availability in the developing countries, obesity is also on the rise in those countries as well (BBC news, June 10, 2013).

Until recently, no one has seriously questioned whether a low-cost food supply has brought anything but benefits to the United States. However, studies are beginning to link the low cost of foods with the obesity epidemic. One study found that technological advances led to a decline in the price of food, which in turn led to higher energy intakes (Lakdawalla \& Philipson, 2005).

Journal of Applied Business and Economics Vol. 20(3) 2018131 
The drop in food price was said to account for up to 40 percent of the increase in body mass index since 1980 (Ibid). The sad part of this result is that the population subgroups with least resources is more vulnerable to the obesity epidemic and any policy changes in terms of higher taxes on unhealthy food will be punitive measures.

\section{Poverty, Inequality and Obesity}

Poverty status or percentage of poverty level is based on family income, family size, and the number of children in the family, and for families with two or fewer adults, on the age of the adults in the family. The poverty level is based on a set of income thresholds that vary by family size and composition. Families or individuals with income below their appropriate thresholds are classified as below the poverty level. These thresholds are updated annually by the U.S. Census Bureau to reflect changes in the Consumer Price Index for all urban consumers. The Census Bureau report of 2013 indicated that the poverty rate in America held stable between 2011 and 2012 at about 15 percent. According to the official measure, poverty today is higher than it was in 1973, when it reached a historical low level of 11.1 percent (Danziger, 2013). In 2012, 14.7 million people in the United States had family incomes between 100 and 125 percent of their poverty threshold. The near-poverty rate for individuals decreased from 6.3 percent in 1966 to 4.7 percent in 2012 (Heggenes \& Hokayem, 2014). The official poverty definition uses money income before taxes and tax credits and excludes capital gains and noncash benefits (such as SNAP benefits and housing assistance). The thresholds do not vary geographically. All things equal, such programs, whether we count them or not, should have reduced the official poverty rate across generations. But all things have not been equal. Although these programs help the poor, poverty remains high because inequality of economic outcomes has increased sharply.

Before income inequality took off, the poverty rate fell more rapidly with GDP growth. But while the economy grew by 2.8 percent in 2012 and corporate profits went up as a share of national income, the earnings of full-time workers, median household income and the poverty rate barley changed. That's not to say that growth is no longer necessary for reducing poverty. But in our age of inequality, growth alone is insufficient, but policies that lower the unemployment rate and increase wages will give more benefits to the poor.

As the Economist magazine notes in its own survey of obesity, "the rich and well-educated have mostly managed to stay slim." Also, it said that obesity is prevalent among the Medicaid and thus is burden to tax payers (Jenkins, 2013). The relationship between obesity and poverty has become more obvious and complex: being poor in one of the poorest countries may be associated with poor nutrition, while being poor in a developed country could mean a higher risk of obesity. This is confirmed by Sobal and Stunkard (1989): in developed countries, there is an inverse relationship between obesity and socioeconomic status, the higher social classes are able to compensate for a sedentary lifestyle, with more information and sport opportunities, plus they can afford better quality food, organic and less processed. In less developed countries, with a \$2,500 GDP per capita, a direct relationship prevails and, excess weight is observed more frequently among the higher social classes (Monteiro et al., 2004).

Existing studies suggest that the high cost of healthier diets may contribute to the obesity epidemic especially among the lower-income group and low-educated group (Tables 3 and 4). At the individual level, obesity rates are linked to low incomes, low levels of education, minority status, and a higher incidence of poverty. Tomer (2011) in his research indicates that socioeconomic groups with low personal capital, low health capital, and low social capital have higher obesity rates than socioeconomic groups with higher endowments of intangible capital. This has been supported by other studies that indicates that higher diet quality, as measured by the Healthy Eating Index, is associated with higher incomes, more education, and with lower rates of obesity and overweight (Henderson, 2007).

According to the following information presented in Table 3 and 4, during 2007-2009 the percentage of obese individuals has been the highest for low-income families (35.3 percent) and the lowest for higher income family ( 24.5 percent). Also, a higher level of education is a contributing factor to a better diet and healthy weight, those with less than high school education had higher percentage of obese (33.6 percent) 
and the one with higher education less percentage of obese (22 percent). This view point is also consistent with Lakdawall and Philipson (2002) findings stating that the obesity problem and poor health status is very much a problem of low-income status.

Although other factors, including addictive personality, stress, and depression, seeking comfort in familiar foods has been among factors leading to higher consumption of sweets and deserts. In addition, physical access to supermarkets and grocery stores, marketing and distribution of healthy foods, urban sprawl, and the time spent commuting to work have also contributed to failure to adhere to healthy diets (Morland et al., 2002). This implies that people with weak and/or negative social capital are more likely to be vulnerable to the influences from the infrastructure of obesity and the economic incentives from the markets regarding food and exercise.

Tomer (2008) argues that in the presence of strong positive social relationships, people's imbalances are likely to be more muted and less problematic. Conversely, when social capital (SC) is weak and negative, people's imbalances are likely to be more pronounced and problematic. Social capital refers to the capacity that is embodied in an individual's social relationships or the bonds and connections between an individual and others. Social capital is embodied in families, institutions, civic communities, and the larger society. The strength and quality of an individual's SC endowment arguably has a relationship to the person's likelihood of becoming obese (Tomer, 2011).

\section{Consequences of Obesity}

Obesity is the second leading preventable cause of death in the United States. Each year approximately 300,000 lives are lost due to the direct or indirect consequences of obesity. Obesity is associated with multiple chronic conditions, such as high blood pressure, high cholesterol, heart disease, and stroke, Type 2 diabetes, uterine, breast, colon and gall bladder cancer. Sleep apnea, arthritis, and depression can also be linked to obesity. There is 50 to 100 percent increased risk of all-cause mortality amongst obese individuals. Around 80 percent of obese individuals have diabetes, high cholesterol, high blood pressure or heart disease. Direct medical costs related to obesity are secondary to preventive, diagnostic and treatment services. Hammond and Levine (2010) measured direct medical costs associated with obesity. They argue that relative medical spending for the obese may be as much as much as 100 percent higher than for healthy weight adults, and nationwide "excess" medical spending may amount to as much as $\$ 147.0$ billion annually for adults and $\$ 14.3$ billion annually for children.

Indirect costs focus on premature mortality, higher disability insurance premium, and labor market productivity (morbidity). Mortality costs include future income lost as a result of premature death. Morbidity costs also factor income lost from decreased productivity, restricted activity, and absence from work. As per the indirect costs related to obesity, obese people tend to be less productive than the average healthy person and they are more subject to the phenomenon of presenteeism (the tendency to go to work even if you are not in optimal physical condition) (Finkelstein et al., 2011). There is growing evidence that obese employees have greater rates of absenteeism and presenteeism. In a recent analysis, Finkelstein et al., (2010) combined multiple data sets to quantify medical expenditures and the value of lost productivity resulting from absenteeism and presenteeism for overweight and obese full time employees. The cost of obesity among full-time employees, in the United States, has been estimated to be $\$ 73.1$ billion per year (Finkelstein et al., 2010), in details: 18 percent due to sick days, 41 percent due to lack of productivity because of health issues, and 41 percent due to general medical expenses. Hence, the hidden or so-called indirect costs related to obesity are a relevant percentage of the total.

There are different estimates of such costs as a result of a confluence of factors such as the date of measurement, representativeness of the sample and the scope of measurement. For example, Thompson et al., (1998) took a look at the total cost of obesity to U.S. businesses, differentiating between health insurance expenditures, paid sick leave, life insurance, and disability insurance. The authors estimate that the total non-medical cost of obesity among U.S. businesses was $\$ 5$ billion in 1994. Of that, $\$ 2.4$ billion was spent on paid sick leave, $\$ 1.8$ billion on life insurance, and $\$ 0.8$ billion on disability insurance.

The economic loss of productivity caused by excess mortality is estimated at $\$ 49$ billion per year in the United States and Canada (Behan \& Cox, 2010). The economic loss of productivity caused by 
overweight or obesity for totally disabled workers is at $\$ 72$ billion (Ibid). Behan and Cox estimated that the total annual medically-related cost of overweight and obese individuals in the United States and Canada is caused by medical costs, excess mortality, and disability and is approximately $\$ 300$ billion in 2009. Medical costs associated with obesity in the United States are estimated to be $\$ 170$ billion in 2013 (BBB News, 2013).

Due to the health consequences resulting from excess weight, the increase in obesity also has profound economic consequences on employers and government: the loss of productivity caused by obese conditions of employees is as high as the medical expenses attributable to such conditions. As per the socalled direct costs generated by obesity, compared to normal weight individuals, it is estimated that obese adults have an average of 19.5 percent more physician visits (Quesenberry et al., 1998; Finkelstein, et al., 2011). Thompson et al., (2001) also found that obese adults have 48 percent more inpatient days per year and 1.8 times more pharmacy dispenses.

Because of the high costs of obesity, and the fact that the majority of these costs are financed by taxpayers, there is a clear motivation for government to try to reduce these costs. However, because obesity may result from poor information and addictive behavior and/or as a result of living in an increasingly obesogenic environment, interventions will need to be multifaceted to ensure the best chance of success (Finkelstein, et al., 2015).

\section{Models to Test Income Inequality, Poverty and Obesity in the United States}

Poverty and obesity varies among states, as indicated in Table $5 \& 6$, where Mississippi has the highest obesity rate of 35.4 percent in 2013 and Montana has the lowest rate of 19.6 percent. Appendix shows the data on obesity for $2010-2012$ for all states.

\section{The Measurement of Income Inequality and if Inequality Makes You Sick}

Various measures are available to quantify the extent of income inequality within a given community or society. Of these, the Gini coefficient is the one frequently used. Gini coefficient varies from $0-1.0$ and it is defined as half of the arithmetic average of the absolute differences between all pairs of incomes in a population, the total then being normalized on mean income. If incomes in a population are distributed completely equally, the Gini value is 0 , and if one person has all the income (the condition of maximum inequality), the Gini is 1.0. The Gini coefficient can also be illustrated through the use of a Lorenz curve as indicated in Figure 1. On the horizontal axis is the percentage of the families and on the vertical axis is percentage of the aggregate income within the society. Under conditions of perfect equality in the distribution of income ( Gini $=0$ )-line (a), each decile group would account for exactly 20 percent of the aggregate income, such that the Lorenz curve would follow the 45-degree line of equality. The Gini coefficient is the ratio of the area between the Lorenz curve and the 45-degree line of equality (line a).

It is widely acknowledged that individual income is a powerful determinant of individual health has made the startling claim that income inequality is the major cause of our nation's health problems (Subramanian \& Kawachi, 2004; Bezruchka, 2001). He dismisses the role individuals can play in safeguarding their own well-being, claiming that "research during the last decade has shown that the health of a group is not affected substantially by individual behaviors such as smoking, diet and exercise." Better prescriptions for a healthy society, he argues, would include a "consumption tax."

Bezruchka is not alone in believing that improving health depends upon transforming economic conditions. Kawachi (2000) in his book "Inequality Bad for Our Health?” declares income inequality an "important public health problem." Indeed, for the past decade public health experts have become increasingly eager to expand their professional agenda beyond health into broader controversies. To be sure, attempts to understand the ultimate non-medical sources of ill health (e.g., education, class, deprivation) have occupied scholars for decades. But there is a huge difference between explicating these factors and claiming scientific authority for political remedies. Indeed, fixating on social transformation as the proper role of public health professionals' risks taking physicians and epidemiologists away from their traditional mission, or trivializing it. That mission is to develop the scientific and practical bases of disease prevention and to devise effective ways to educate the public about health risks. 
None of this is to deny that social conditions, especially poverty, affect physical well-being and length of life. And public health practitioners do have a responsibility to design policies that reliably prevent disease, reduce contagion, and minimize injury. But they are sorely mistaken in thinking they have special expertise in changing the income distribution, in defining social justice, or in producing the instruments that can attain it.

A central premise of new public health scholarship is the "income-inequality" hypothesis. This hypothesis has spawned a minor academic industry, which has produced some important and carefully drawn epidemiological studies. It has also produced a surprising volume of ideologically driven speculation that fails to withstand critical scrutiny.

The hypothesis reached a wide audience in the early 1990s through the publications of Wilkinson (1996) who claims the causal link between income inequality and individual health represents the most important limitation on the quality of life in modern societies. From this he concludes there is "a persuasive case for the redistribution of income. Wilkinson and others point to data purporting to show that health and longevity are, in large part, determined by relative wealth. For example, wealthy countries with more equal income distributions, such as Sweden and Japan, have longer life expectancies than the United States.

Kawachi et al., (1999) expand on Wilkinson's thesis. "The health of a population depends not just on the size of the economic pie, but how the pie is shared. The authors speculate on how social inequality produces differences in health at each step on the socioeconomic ladder. "Income inequality," they observe, "appears to affect health by undermining civil society. . . . Lack of social cohesion leads to lower participation in political activity (such as voting, serving in local government, volunteering for political campaigns)." And lower participation, in turn, reduces government spending on public goods, such as education, and social safety nets.

Other public health scholars point to the disease-producing anxiety of not being able to keep up with the Joneses. As Lynch and Kaplan (1997) argues that health may be affected through individual appraisals of relative position in social order. Even those with good incomes might feel relatively deprived compared to the superrich.

There is in fact intriguing evidence that a person's socioeconomic position can affect health. Consider Marmot et al., (1991) who examined workers in the five grades of the British Civil Service; all had access to health care and at least a decent income. It was no surprise to the researchers that civil servants at the lowest grades suffered heart disease at about three times the rate of men at the top tier. But they were puzzled to discover that even highly paid professionals in the fourth category had twice as much heart disease as the workers right above them. What appeared to explain this finding was the fact that these workers had little "control of destiny" - their jobs were heavy with responsibility, but with relatively little authority. Illness is caused by the power imbalance in a capitalist society," insists Braveman (2006). She argues that we must counteract the free market with social programs.

For those like Braveman who condemn capitalism, it is a small step to say that income inequality is the issue. Yet there are fundamental problems with the evidence upon which their arguments for the redistribution of income are based. Pollack questioning the very measures of inequality typically citedindices of income dispersion. He argues that in practice, it is very difficult to distinguish the potential health effects of income inequality from the strong effects that arise from absolute need. To those at the bottom of the economic ladder, it may be the ability to meet daily needs that matters most, not relative status. In this reading of the evidence, money is meaningful to the poor because of what it can buy, not because they have less of it than others. Thus, it is not so much income dispersion itself that matters for health but the proportion of the population that suffers true poverty-related problems, such as undernourishment, lack of access to timely medical care, and so on. Pollack points out, the health impact of inequality itself is really unknown, once one controls for closely connected characteristics like race. What we are left with is energetic advocacy of a deeply uncertain claim about the connection between health and the degree of income inequality (Satel \& Marmor, 2001).

There are also dangers in concluding from the relationship between health and wealth that being less well-off produces disease. Indeed, the so-called healthy worker effect suggests an opposite reading: that 
health may determine income. After all, people who are healthier are more likely to hold jobs and to work competitively, activities that help them advance both their social and economic positions and, in turn, protect their health. We have to be cautious in generalization about generalizations about the longevitythreatening effect of a socially stratified society as there are some striking exceptions to the incomeinequality schema. For instance, in Denmark, the gap between the top and bottom of the income scale is smaller than in the United States, yet its citizens have a lower average life expectancy than ours. The Japanese have the longest life expectancies, but their social hierarchy is very rigid.

The relationship between obesity and socioeconomic status differs by sex and race and ethnicity group. Among women and specifically non-Hispanic white women, obesity prevalence increases as income decreases, while among non-Hispanic black and Mexican-American men obesity prevalence decreases as income decreases. Although the prevalence of obesity among women with income below $130 \%$ of the poverty level is higher than among those with higher incomes, most obese women do not have incomes below $130 \%$ of the poverty level. Among men and women with a college degree, the prevalence of obesity is lower than among those with some college education. Moreover, college educated women are less likely to be obese compared with those with less than a high school diploma. Between 1988-1994 and 2005-2008 the prevalence of obesity increased in adults at all levels of income and education (Ogden, et al., 2010).

\section{DATA AND METHODOLOGY}

\section{Specification of the Models}

In this paper, we are going to follow Subramanian and Kawachi's (2004) model of intrinsically multilevel nature of the income inequality hypothesis by contrasting the individual-level and aggregatelevel models. Using typical regression notations, we can specify the individual-level relation between income and health as follows:

$y_{i}=\beta^{*}\left(x_{i}\right)+e_{i}$,

where $y_{i}$ is the health status of individual $i ; x_{i}$ is the income of individual $i ; \beta^{*}$ represents the nonlinear (or concave) nature of the relation between $y_{i}$ and $x_{i}$; and $e_{i}$ is the residual differences in individual health, after accounting for individual income. Making the usual independent and identical distribution assumption that the residual individual-level differences follow a normal distribution with a mean of zero, have a constant variance, and are independent of one another. we can summarize the residual differences through a variance parameter. It may be noted that equation 1 will also typically include an "intercept" parameter (associated with a constant) and, since it is not of interpretative significance, in this instance, we did not explicitly include this in our equations.

Meanwhile, the aggregate (societal) level relation between income inequality and health can be expressed in the following way:

$y_{j}=\alpha\left(W_{i}\right)+u_{i}$

where $y_{j}$ is the average health of a society $j ; W_{i}$ is the income inequality in society $j$ (measured by Gini-coefficient) ; $\alpha$ estimates the relation between $y_{j}$ and $W_{i}$; and $u_{j}$ is the residual differences in societal health, after accounting for societal level income inequality. Following the above independent and identical distribution assumptions, one can summarize these societal differences in a variance parameter,

Although equations 1 and 2 apparently allow us to test the "concavity effect" and the "pollution effect" respectively, they do so separately. Concavity effect means the relation between income and health at the individual level is linear (not concave), such that each additional dollar of income raises individual health by a decreasing amount, then the implication of this is that a transfer of income from the rich to the poor will reduce the level of income inequality but will not lead to improvements in the average health status of that society. Hence, throughout the rest of this paper, we shall use the term "concavity effect" to 
describe the expected relation between income inequality and population average health status, when the shape of the association between individual income and health is concave.

The distribution of income in society, over and above individual incomes as well as societal average income, matters for population health such that individuals (regardless of their individual incomes) tend to have worse health in societies that are more unequal. Thus, income inequality per se may be damaging to the public's health by causing a downward shift in the income/health curve. We refer to the independent contextual income inequality effect as the "pollution effect" of income inequality on health.

The above distinctions, therefore, are not between the "effects of individual income" on health and the "effect of income inequality" on health. Rather, they distinguish the "concavity-induced income inequality effect" from that related to the "income inequality as a societal effect."

By contrast, the "income inequality hypothesis" demands testing the two effects simultaneously in order to ascertain the independent (as well as the relative) importance of each of the two, and one way of expressing this would be

$y_{i j}=\beta^{*}\left(x_{i j}\right)+\alpha\left(W_{i}\right)+u_{j}+e_{i j}$,

where $y_{i j}$ is the health status of individual $i$ in society $j ; x_{i j}$ is the income of individual $i$ in society $j$ (with $\beta^{*}$ estimating the nonlinear (or concave) nature of the relation between $y_{i j}$ and $x_{i j}$ within a society); and $W_{j}$ is the level of income inequality in society $j$ (with $\alpha$ estimating the effect of societal income inequality on individual health) having taken account of the individual income-health relation. An important aspect of the specification in equation 3 is that variation in health status is seen to be coming from two sources, that is, individual $\left(e_{i j}\right)$ and society $\left(u_{i}\right)$, and the variation attributable to the level of individuals and to the level of societies is appropriately partitioned. Thus, underlying the combined model presented in equation 3 are two models: a "micro" model capturing the between-individual-withinsociety relation nested within a "macro" model specifying the between-society relation. Accordingly, explanatory variables of interest are also correctly specified according to their distinctive levels (e.g., income at the individual level and income inequality at the societal level). Typical single-level regression models are inadequate since they anticipate and model only a single source of variation (e.g., equations 1 and 2) and, as such, "multilevel regression models" (also referred to as hierarchical mixed and randomeffects, covariance components or random-coefficient regression models) of the form specified in equation 3 are required to specify the income, income inequality, and health relation.

In this study we try to identify the cointegration relationship among obesity, income inequality and poverty. Obesity ( $l$ obese) is measured by the BMI index in which the person is to be called obese if his $\mathrm{BMI} \geq 30.0$. This data is expressed as the average of all BMI $\geq 30.0$ in each state in the USA. ${ }^{1}$ We make a proxy for health status by obesity. The variable income inequality $\left(l \_\right.$gini $)$is measured by the Gini coefficient at the state level. Poverty (l poverty) is measured by poverty rate as given by US Census Bureau. ${ }^{2}$ So, we can identify the following econometric specification for panel data as following

$l_{\text {_obese }}{ }_{i t}=\alpha_{i}+\beta_{1 i} l_{\text {_ }}$ gini $_{i t}+\beta_{2 i} l_{\text {_ }}$ poverty $_{i t}+\varepsilon_{i t}$

where each variable is expressed in natural logarithmic form and $i=1,2, \ldots, n ; t=1,2, \ldots, T$.

\section{Panel Unit Root and Cointegration Tests}

The integration and cointegration properties of the variables involved determine the specification of obesity. If the series are integrated, equation (4) should be viewed as a long run relationship. Otherwise, a short run interpretation is appropriate. It has been widely acknowledged that standard unit root and cointegration tests can have low power against stationary alternatives for the important cases, see for example Campbell and Perron (1991). As an alternative, recently developed panel unit root and cointegration tests are applied. Since the time series dimension is enhanced by the cross section, the results rely on a broader information set. Thus, gains in power are expected, and more reliable evidence 
can be obtained. Furthermore, many of the time series tests have limiting distributions, which are complicated functional of Wiener processes. In contrast, panel tests lead to statistics with Gaussian distribution in the limit. On the other hand, new problems are introduced. In particular, cross section cointegration may bias the panel tests, see Banerjee et al., (2001).

Here, the LLC (Levin, Lin and Chu, 2002, here after LLC), the IPS (Im, Pesaran and Shin, 2003, here after IPS) and Breitung (Breitung, 2000) tests are considered. Deterministic and dynamic effects in the data generating process might differ across the panel members. The first two procedures are generalizations of the ADF principle. The null of a unit root is investigated against the alternative of a stationary process for all (LLC) or at least for one cross section (IPS). Breitung (1999) finds that IPS suffers a dramatic loss of power when individual trends are included, and the test is sensitive to the specification of deterministic trends. For the LLC and IPS test, the optimal lag length is selected using the general-to-simple procedure proposed by Campbell and Perron (1991). The consistent estimator of the long run residual variance relevant for the LLC statistics is obtained using the Bartlett kernel and the automatic bandwidth parameter suggested by Newey and West (1994). Provided that the degree of cross section correlation is not substantial, the statistics

$$
z_{t}=\frac{z_{t}^{*}-\mu}{\sigma}
$$

are asymptotically distributed as standard normal with a left (LLC, IPS) hand side rejection area. Standardization factors are obtained by simulation and depend on the deterministic components included in the testing procedure.

For panel cointegration, the tests suggested by Pedroni (1999) are employed. They extend the Engle and Granger (1987) two step strategy to panels and rely on ADF and PP principles. First, the cointegration equation is estimated separately for each panel member. Second, the residuals are examined with respect to the unit root feature. If the null of is rejected, the long run equilibrium exists, but the cointegration vector may be different for each cross section. In addition, deterministic components are allowed to be individual specific. The residuals are pooled either along the within or the between dimension of the panel, giving rise to the panel and group mean statistics (see Pedroni, 1999). In the case of the panel statistics the first order autoregressive parameter is restricted to be the same for all cross sections. If the null is rejected, the parameter is smaller than 1 in absolute value, and the variables in question are cointegrated for all panel members. In the group statistics, the autoregressive parameter is allowed to vary over the cross section, as the statistics amount to the average of individual statistics. If the null is rejected, cointegration holds at least for one individual. Hence, group tests offer an additional source of heterogeneity among the panel members. Overall, seven tests are proposed. In the limit, the statistics are distributed as standard normal with a left hand side rejection area, except of the variance ratio test, which is right sided. Standardization factors arise from the moments of Brownian motion functionals. The factors depend on the number of regressors and whether or not constants or trends are included in the cointegration relationships.

In addition, the Kao and McCoskey (1998) LM test for the null of cointegration is applied. The long run is estimated by efficient methods carried out separately for the panel members. Then, the cointegration residuals are pooled, and the test statistic is asymptotically Gaussian with a right hand side rejection area.

It is important to note that the panel cointegration tests do not provide an estimate of the long run relationship. More or less, the cointegration vector should be common for the panel members, as fundamental economic principles are involved. Also, hypothesis testing is a critical issue. In fact, the asymptotic distribution of the OLS estimator depends on nuisance parameters. In a panel environment, this problem seems to be more serious, as the bias can accumulate with the size of the cross section. To overcome these deficits, efficient methods like fully modified least squares (FMOLS) and dynamic ordinary least squares (DOLS) are required. As these techniques control for potential endogeneity of the 
regressors and serial correlation, asymptotically unbiased estimates of the long run can be obtained. The methods are asymptotically equivalent (Banerjee, 1999). Hence, their relative merits boil down to a comparison in finite samples. In the FMOLS case, nonparametric techniques are used to transform the residuals from the cointegration regression and get rid of nuisance parameters (Phillips, 1995; Pedroni, 2001). In the time series model

$$
\begin{aligned}
& y_{i t}=\alpha_{i}+\beta_{i} x_{i t}+u_{i t} \\
& x_{i t}=\lambda_{i} x_{i t-1}+\varepsilon_{i t} \\
& \varpi_{i t}=\left(u_{i t}, \varepsilon_{i t}\right)^{\prime}
\end{aligned}
$$

the asymptotic distribution of the OLS estimator is conditioned to the long run covariance matrix of the joint residual process. The FMOLS estimator for the $\mathrm{i}$-th panel member is given by

$$
\hat{\beta}^{*}=\left(X_{i}^{\prime} X_{i}\right)^{-1}\left(X_{i}^{\prime} y_{i}^{*}-T \hat{\delta}\right)
$$

where $y^{*}$ is the transformed endogenous variable and $\delta$ a parameter for autocorrelation adjustment. Appropriate correction factors are based on certain submatrices of the joint long run covariance matrix. In the DOLS framework, the long run regression is augmented by lead and lagged differences of the explanatory variables to control for endogenous feedback (Saikkonen, 1991). Lead and lagged differences of the dependent variable can be included to account for serial correlation (see Stock \& Watson, 1993). In particular, the equation

$$
y_{i t}=\alpha_{i}+\beta_{i} x_{i t}+\sum_{j=-p_{1}}^{p_{2}} \delta_{j} \Delta y_{i t-j}+\sum_{j=-q_{1}}^{q_{2}} \psi_{j} \Delta x_{i t-j}+u_{i t}
$$

is run for the i-th panel member, where the appropriate choice of leads and lags is based on data dependent criteria (Westerlund, 2005). Standard errors are computed using the long run variance of the cointegration residuals.

In a panel setting, the cointegration relationship is homogeneous. Heterogeneity is limited to fixed effects, time trends and short run dynamics. The panel FMOLS estimator is the average of the individual parameters (see Pedroni, 2001). According to Mark and Sul (2002) a panel DOLS estimator is obtained using a two-step procedure. First, individual dynamic and deterministic components are regressed out separately for the panel members. Then, the residuals are stacked, and a pooled regression is run. As an alternative to these methods, Breitung (2002) has suggested a two-step procedure based on a cointegrated VAR model. In the VECM

$$
\Delta z_{i t}=\alpha_{i} \beta^{\prime} z_{i t-1}+\varepsilon_{i t}
$$

the feedback coefficient $\alpha_{\mathrm{i}}$ and the covariance matrix $\Sigma_{\mathrm{i}}$ of the residuals are allowed to vary across the individuals. As the information matrix of the Gaussian likelihood is asymptotically block diagonal with respect to the short run and cointegration parameters, the long run relation can be uncovered conditional on consistent estimates of the former. Hence, the short run parameters are revealed by individual VECM's, and the restriction that the individuals have a common cointegration vector is temporarily ignored. Then, the variables are transformed according to

$$
\begin{aligned}
& z_{i t}^{*}=\beta^{\prime} z_{i t-1}+\varepsilon_{i t}^{*} \\
& z_{i t}^{*}=\left(\hat{\alpha}_{i}^{\prime} \hat{\Sigma}_{i}^{-1} \hat{\alpha}_{i}\right)^{-1} \hat{\alpha}_{i}^{\prime} \hat{\Sigma}_{i}^{-1} \Delta z_{i t}, \varepsilon_{i t}^{*}=\left(\hat{\alpha}_{i}^{\prime} \hat{\Sigma}_{i}^{-1} \hat{\alpha}_{i}\right)^{-1} \hat{\alpha}_{i}^{\prime} \hat{\Sigma}_{i}^{-1} \varepsilon_{i t}
\end{aligned}
$$


and a pooled regression is run. The long run parameters are asymptotically distributed as standard normal. According to simulation evidence provided by Breitung (2002), his estimator is preferable over FMOLS and DOLS alternatives, as it comes with a smaller finite sample bias.

As a major shortcoming, the panel tests for integration and cointegration presume that the cross sections are independent. However, this requirement is not met in the analysis presented here. For example, medical advancements and income are correlated across states. In particular, the presence of cross section cointegration can distort the panel results, see Banerjee et al., (2004) and Urbain (2004). In these cases, either the endogeneous variable or specific regressors cointegrate across the panel members. To control for this problem, cointegration tests based on nonstationary common factors are proposed, see Bai (2004), where factors are obtained as principal components. Compared to the individual state analysis, the procedure is likely to be more robust, because idiosyncratic (state specific) parts cancel out.

\section{RESULT DISCUSSION}

The obesity equation (4) is estimated for a sample of 50 states of USA using annual series taken from US Census Bureau, Center for Disease Control and Prevention, USA from 1995 to 2012. All variables are in logarithmic form.

The first step is to check for the integration properties of the variables involved. Table 7 shows the results of the panel unit root tests. The level method has been specified with fixed effects and state individual time trends in the data generating process. The time trends amount to fixed effects in the first difference specification.

More or less, a unit root is detected for the level variables, while the first differences appear to be stationary. Due to this result, each variable includes a random walk component. Table 8 shows the results of unit root test for the variables in their first-differenced form.

The panel cointegration tests point to the existence of a long-run relationship between obesity and income inequality and poverty, see Table 9.

For example, the null of no cointegration is rejected by most of the Pedroni (1999) tests at $1 \%$ level. Specifically, when we consider intercept and trend case, both the panel statistics and group statistics reject the null of no cointegration in all tests.

We also performed the cointegration test proposed by Kao and McCoskey (1998) where null hypothesis is no cointegration. We also see that the test confirms the long-run relationship among the variables as the test rejects the null of no cointegration. Table 4 shows the Kao and McCoskey (1998) test of cointegration.

After the confirmation of long-run relationship, the next step is to estimate the long-run relationship using FMOLS or DOLS. ${ }^{3}$ Then we present both the FMOLS and DOLS results. The regressor enters with the correct sign and they are highly significant.

Table 11 shows the cointegrating regression using FMOLS method. Both of the regressors are highly significant. It is to be noted that both of the coefficients represent the elasticity of obesity with respect to each variable. Our results suggest that income inequality is more responsible for the obesity than poverty as the elasticity of obesity with respect to income inequality is greater than that of with respect to poverty.

Table 12 show the same result when DOLS method is used. This result also resembles with the FMOLS result. Although the coefficient of $l$ poverty is insignificant, the signs of the coefficients resemble with the FMOLS result.

Both of the long-run cointegration estimations confirms that there is a long-run relationship among obesity, income inequality and poverty and the relationship is positive. This positive relationship urges for some explanation regarding obesity. As poverty induces the consumer to purchase low-quality of food which increase the probability of having obesity, reducing poverty level can mitigate the problem of obesity. On the other hand, income inequality often retards the consumer to purchase high quality of food. Reducing income inequality and poverty have a broad impact to reduce obesity both in the micro and macro level. 


\section{Mixed Model Methodology}

So far we have examined the relationship between obesity, income inequality and poverty at state level. Although our results of panel co-integration and long-run model establish the desired relationship, we will present the mixed model methodology to see the robustness of our earlier results. One of the key findings will be to check the positive association of income inequality and the level of poverty with the obesity level at state level. In particular, we examine the error variance resulting from the differences in state level inequality and poverty.

Methodology

Suppose there are $j(j=1,2, \ldots, \mathrm{n})$ number of state and the time span is $t(t=1,2, \ldots, \mathrm{T})$ and we are measuring the obesity level for each state along with the poverty and inequality. The definition of variables have stated in previous section. Following literatures, we have

$y_{i j}=\mu_{i}+\varepsilon_{i j}$

where $y$ is the dependent variable, $\mu_{i}$ is the true value which we assume come from some distribution an $\varepsilon$ is the measurement error term. We also assume that $E\left(\mu_{i}\right)=\mu$ and $\operatorname{Var}\left(\mu_{i}\right)=\sigma_{b}^{2}$ where $b$ stands for between-subject variation. $\varepsilon_{i j}$ are measurement and are independent of each other. We also assume that $E\left(\varepsilon_{i j}\right)=0$ and $\operatorname{Var}\left(\varepsilon_{i j}\right)=\sigma_{w}^{2}$ where $w$ is the within-subject variation. In the measurement error literature, this is called 'classical measurement error'. It is also the same as the model used in one-way analysis of variance (ANOVA), with the grouping variable treated as random. It is also a very simple random-effects model - the random-intercepts model (see Kim \& Frees, 2007).

The above table, Table 13 shows the estimation of multilevel mixed model of equation (11). We assume that the there is a 'state' effect and the variables like income inequality and poverty also affect the obesity rate.

Model 1 shows that the variation comes from the state level where the coefficient of constant term is highly significant. Model 2 and Model 3 show that the effects of poverty and inequality are also positive and highly significant. The random effects parameters are significant as their standard deviation are less than 1. All of the LR test statistics reject the null hypothesis of no significant difference between the two models depicting that random coefficients model provides a better fit. We stated earlier with our objective to perform this robust analysis. This analysis suggests that there is a strong relationship among state level obesity rate, income inequality and poverty.

\section{FOOD POLICY INTERVENTIONS}

Without effective intervention, the costs of obesity might well become catastrophic, arising not only from escalating medical expenses but also from diminished worker productivity, caused by physical and psychological disabilities. Future economic losses could mean the difference between solvency and bankruptcy for Medicare, between expanding and shrinking health care coverage, and between investment in and neglect of our social infrastructure, with profound implications for our international competitiveness. The human costs would be incalculable (Ludwig, 2007).

Although broad consensus exists regarding the dietary and lifestyle habits needed to prevent and treat childhood obesity, we lack anything resembling a comprehensive strategy for encouraging children to eat a healthful diet and engage in physical activity. Such a strategy would include legislation that regulates junk-food advertising, provides adequate funding for decent lunches and regular physical activities at school restructures in the farm-subsidies program to favor nutrient-dense rather than calorie-dense produce, and mandates insurance coverage for preventing and treating pediatric obesity (Ludwig, 2007). The fact is that a single coordinated public policy that addresses the obesity infrastructure is highly unlikely due to the various interest groups and lobbyists at the federal, state and local levels (Hojjat \& Hojjat, 2017). 
Parents must take responsibility for their children's welfare by providing high-quality food, limiting television viewing, and modeling a healthful lifestyle. Fortunately, with the exercise of both personal and social responsibility, we have the power to choose the shape of things to come.

Food policy interventions at the national and international level may be the most promising approach to making healthy food affordable and accessible to all. The World Health Organization (WHO) stated that the key to maintaining a healthy weight is an affordable supply of fresh nutrient-rich foods. Such access could be facilitated through a combination of agricultural subsides, pricing policies, regulatory action, and consumer education. This approach would require cooperation between government, academia, and the food industry.

Many variables influence diet and lifestyle choices. Food prices and income status are important determinants of what we will consume. Other factors such as taste, convenience, age, family size, knowledge, and health status are just as important. There are two main policy approaches to address obesity. One approach is to reduce the demand for products and to change the lifestyle that contributes to obesity. This approach can be achieved by information, education, taxing products and food labeling etc. The second approach is to reduce the supply side by cutting subsidies of agricultural products that keep the costs low.

There have been several suggestions to not only remove the offending foods from the consumers' reach, but also to discourage consumption and promote alternative healthier diets. This can be achieved through imposing taxes on fats and sweets and nutrition can be improved at schools by limiting access to vending machines containing beverages and snacks and regulating the sales of competitive foods. Agricultural policy options include the provision of economic incentives for the production of healthier foods and removal of existing subsides. Recent research has uncovered the baneful influence that cornbased sweeteners have had on America's obesity epidemic. It is estimated that Americans consume 73 percent of corn-derived sweeteners per person per year (Huntrods \& Koundinya, 2012). Michael Pollen (2006) points out; the growth of corn-based sweeteners is a direct result of the government's farm policy, which subsidizes corn production. A basic consequence of economic law is that when something is subsidized, more of it will be produced while calories from high-fructose corn syrup are unhealthier than those from natural sweeteners, such as sugar.

Children spend a significant portion of time in schools making it natural that the eating habits acquired during school years become life-long. In America, 17 percent of children under 20 are obese or about 12.5 million people, according to the Centers for Disease Control and Prevention (n.d). The rate has tripled since 1980, has leveled off in recent years but has remained at historical highs, and public health experts warn that it could bring long-term health risks (Tavernise, 2012). It is mostly the result of access to foods that have limited nutritional value which are widely promoted. According to the Center for Disease Control's study, 33 percent of elementary schools had canteen, snack shop or vending machines in 2006. Most of the foods sold are of poor nutritional quality. Children in the Unites States consume on average almost three times as many calories from sugar-sweetened beverages, compared with Dutch children (Ibid).

Ludwig (2007) suggests there is a need for public policy changes, speaks to the importance of both education and regulation. "It suggests that if we want long-term changes in body weight, we will need to make long-term permanent changes in the environment for children" (Ludwig, 2007). Education matters, but it is not enough, it must be accompanied by restrictions that curb unhealthy habits and with environmental changes that foster healthier ones.

Soft drinks sold in schools are high in calories and add little nutritional value. Increased consumption of these sweetened beverages is linked with higher incidence of obesity and diabetes. The following steps can lead to significant change in the food environment in schools and eventually cultivate healthy eating habits in children:

1. Sell only high nutritional food in schools consisting of fruits, vegetables, whole grains and dairy products that are non-fat. 
2. Distribute water and low or non-fat milk in schools instead of sweetened beverages and fruit juices.

3. INCREASE the reimbursement rates so that school administration can serve food that has high nutritional value.

4. Provide training to food service staff on nutrition and healthy eating.

There have been few research reviews, however, that have shown an association between linking increased availability of fruits and vegetables to increased consumption.

\section{Menu Labeling}

Americans consume one third of their caloric intake from fast foods and restaurants because they are inexpensive and convenient. Consumers are mostly ignorant of the food calories, content of sodium, sugar or fat in the food they eat. People who eat outside of their homes are more likely to consume supersized portions and it has been estimated that adults who eat outside consume 250 more calories per day. Portions served in fast foods and restaurant chains have been increasing since 1970s. National public opinion polls show that around 83 percent of Americans are in favor of menu labeling. Adults often read food labels and make purchasing decisions based on it. Menu labeling provides nutritional information regarding calories, carbohydrates, and fat and sodium content. Currently, restaurants that have this information mostly present it on posters or websites but do not make it readily accessible to consumers when they are making food decisions.

\section{Taxation, Subsidization and Reducing Income Inequality}

A tax placed on a product leads to an increase in its ultimate price. Price increases lead to a reduction in the quantity consumed. This occurs as consumers either cut down or stop purchasing the product. Taxes on items such as alcohol and tobacco have been shown to reduce their consumption. One way to reduce the demand of unhealthy food is to impose tax on items that are most closely associated with obesity. Taxation alone is unlikely to address the problem; however, it does have several benefits. The revenue gained from taxation can be directed towards consumer education, providing exercise facilities and therefore lowering the public costs of health care. Another option is to impose taxes on restaurant franchises, which will ultimately reduce the supply of restaurants. Similar taxes can be imposed on snack vending machine and restaurants. Poor diet by specific populations can be targeted by taxing products in particular locations.

According to data from the Rudd Center for Food Policy and Obesity at Yale University, 17 states filed legislation in 2009-2010 to expand soda taxation; two of these states, Colorado and Washington, passed such legislation. There have been studies to investigate the potential for soft drink taxes to combat rising levels of child and adolescent obesity through a reduction in consumption. Fletcher et al., (2010) results, based on state soft drink sales and excise tax information between 1989 and 2006 and the National Health Examination and Nutrition Survey, suggest that soft drink taxation, as currently practiced in the United States, leads to a moderate reduction in soft drink consumption by children and adolescents. However, they showed that this reduction in soda consumption is completely offset by increases in consumption of other high-calorie drinks.

In general, tax distorts market functioning and reduces economic efficiency. Proponents of soda taxation argue that it falls into the realm of a "pigovian tax." Such a tax may actually increase total economic efficiency in the presence of externalities from consumption. Therefore, taxing such a good not only increases revenue for the government, but may also improve overall welfare by reducing "overconsumption" of the good. In the case of the soda tax, reducing consumption may reduce average body weight and obesity rates (McGranahan \& Schanenbach, 2011). This, in turn, might reduce health problems related to obesity, such as diabetes and heart disease, and could reduce health care expenditures. It usually does not matter whether a tax is imposed on the producers or consumers of a good, because the producers can pass some of the tax on to the consumers, how much of that tax passes on to the consumers depends on elasticity of demand and supply for the product. McGranahan's found out that average 
household spending on sugar-sweetened beverages (SSBs) is $\$ 142$ in 2008. In addition, SSBs represent a larger share of the spending of the poor than is true for the overall population. Also, SSBs consumption as a share of total spending falls as educational attainment increases. As a result, a soda tax would likely have a disproportionate effect on the less educated and poor groups.

Whether an increase in soda taxes can have any potential impact on public health, we can review a few findings: a recent study by Fletcher et al., (2010) finds that the soda taxes do not reduce obesity rates. Recent proposals, however, suggest raising the tax rates to levels much higher than those that are currently seen and may, therefore, lead to a different outcome if tax is high enough to affect the price to reduce consumption. Recent research suggests that soda consumption is modestly responsive to price changes. According to Andreyeva et al., (2010), an increase in the soda price of 10 percent would decrease consumption by between 2.7 percent and 8.1 percent (elasticity of 0.27 to 0.81 ). Second, lower soda consumption would need to result in a reduction in overall caloric consumption in order to be effective. An alternative to increased consumption of healthy food is subsidization of healthy foods; lowering their price will eventually lead to an increase in their supply and price.

Research by the University of Illinois's, Powell and Chaloupka (2009) found that existing state taxes on sugary drinks have not reduced soda consumption nor obesity significantly. But those taxes are relatively small and a heftier tax would probably have some impact, he said. Still, he said people have many other sugar sources apart from sodas - which makes a soda tax different from, say, a tobacco or alcohol tax. Chaloupka noted in the Wall Street Journal, August 13, 2012, that some municipalities have taxed sugary drinks in the form of a license fee. The Richmond and El Monte levies are structured as business license fees imposed on merchants - not as taxes on each drink purchase, meaning it would be up to the sellers to decide how to pass along the added costs. Thus, the effectiveness of imposing tax of sugar sources depends on how it affects the price of the products and hence consumptions. Despite this argument, since 2014, taxes intended to reduce soda consumption have been enacted in seven American cities.

Gradually some actions are being taken in response to corporate responsibilities on obesity. For instance, Coca-Cola Co., PepsiCo Inc., and Dr Pepper Snapple Group will start displaying their drinks' calories on vending machines next year and pointing consumers toward less sugary versions. This was their latest response to critics who have singled them out for contributing to the nation's obesity epidemic.

Finally, leveling the playing field by extending subsidies and insurance programs more widely to fruits and vegetable producers could be a positive step toward fighting obesity. Any new farm bill should, at the very least, remove the current perverse incentives for people to eat unhealthy.

As indicated in other segment of this paper, income inequality appears to affect health by undermining civil society. With lack of social cohesion and lower participation in political activity, less government spending on public goods education and social safety nets will take place. Therefore, any policy to reduce income inequality gap in turn can be linked to health and socioeconomics success. Even if the link between inequality and health were clearly established, the public health profession has no particular expertise in designing policies to reduce inequality and solving the problems of social justice. On the other hand, climbing rates of HIV/AIDS among minorities, epidemic levels of obesity, low rates of screening for cancer and high blood pressure, all of these call for attention.

\section{Access to Healthy Food in Low-Income Areas}

There is not equal access to nutritional food for all Americans. Minorities and low income people have insufficient consumption of healthy foods. There are several reasons for this such as increased cost of fresh foods in low income neighborhoods, lack of public transportation to supermarkets, and few supermarkets and grocery foods in low income areas stock healthy foods.

To increase access to healthy foods the following steps can be taken:

1. Tax incentives to attract supermarkets to low income areas

2. Increased access to public transportation

3. Provide incentives to create farmers markets

4. Providing coupons to purchase healthier foods 
5. Mechanisms to purchase food directly from farms such as farmers markets or/and farm stands.

One community based intervention showed that WIC recipients who received $\$ 10$ weekly vouchers for healthy foods increased their consumption of fruits and vegetables.

\section{Roles of Advertising and Technology}

Highly processed foods were mostly focused in advertisements. Analysis of data for more than 13,000 children found that there is a significant association between the amount of time children spent watching television and the prevalence of obesity. Dietz and Gortmaker (1985) concluded that, among 12to-17 years old, the prevalence of obesity increased by 2 percent for each additional hour of TV viewed, even after controlling for other variables such as prior obesity, race, and socio-economic status. Also, these hours spend watching television contributed to a sedentary life style and an increased risk for obesity. According to the American Psychological Association, children under the age of two are more likely to accept the advertiser's messages as truthful, accurate and unbiased. Food products mostly marketed to children include cereals, candies, sweets, sodas and snack foods. Australia, Canada, Sweden and Great Britain have adopted regulations that prohibit advertising in programs watched by young children. Media also influences behavior in a positive manner. Options include the reduction or regulation of food advertisements that target children, the promotion of educational programs that promote healthy eating and exercise, and intervention to reduce the time children spend on media and texting.

Because the food industry to a certain degree has failed to self-regulate, government regulation of food advertising is necessary to reverse the childhood obesity epidemic. Companies are not adhering to any uniform standards: rather, each company sets its own standard, which means the monitoring compliance is going to be quite difficult. Even more problematic is this: at no point has the entire food industry agreed to restrict marketing to children as it is a profitable endeavor, and it has been a powerful lobby that is difficult to regulate without significant grassroots pressure from advocacy groups (Hojjat $\&$ Hojjat, 2017).

\section{CONCLUDING COMMENTS}

Unlike in the rational obesity model, the individual is not maximizing utility or targeting a particular weight or net calorie consumption. The individual may have some aspirations, but these aspirations are likely to be for a complex combination of health, good looks, and weight. Further, the decision-making outcome will be determined to a great extent by the relative strength of the internal and external factors. If the negative external factors (environment) get stronger over time, as they apparently were during the last three decades, without any significant changes in the internal factors, this would indicate a rising level of obesity as has been observed.

Richmond's City Council agreed to put a measure on the November 2012 ballot to charge businesses a penny for every ounce of those beverages they sell in the city. If it passes, it would be the first city tax of its kind in the nation and the first to be approved by voters. Meanwhile, health advocates from organizations such as Yale University's Rudd Center for Food Policy \& Obesity are saying the measure could help address the nation's obesity problem. Health advocates believe a passage of the tax could set a model for other cities, even as several local soda-tax efforts in various states have been founded amid heavy lobbying. Already, 30 states, including Texas and Iowa, levy a sales tax on purchases of sweetened drinks, averaging about 5 percent, aimed at curbing obesity and raising money. Reduction in unhealthy beverage consumption is needed to help reduce obesity, especially in the lower per capita income areas that have higher obesity prevalence.

Limited access to supermarkets contributes to the risk of obesity because larger supermarkets are more likely to carry healthy foods at affordable prices. In comparison with smaller grocery and convenience stores, supermarkets tend to offer a greater variety of healthier foods. Overall, the number of food stores in poor neighborhoods is nearly one-third lower than in wealthier areas, and the quality of 
these stores - their size and physical condition, the range and nutritional content of their merchandise tends to be poorer (Mantovani et al., 1997).

Finally, the influence of technology on how individuals spend their free time has to reducing physical activity levels. Personal computers, cell phones, and the growing popularity of text messaging have all fostered sedentary behavior among Americans. While some people find these devices to be enjoyable or efficient, others note that individuals "pay" for this very utility by reducing the calories they would have expended by walking next door to talk with neighbors or by engaging in leisure-based exercise.

Food policy intervention through either public interest groups or through government is the key to fight against obesity. There is no single strategy that can be effective alone and rather a combination of different approaches is needed for success. In preventing addiction to tobacco products, the most effective approach was preventing people from becoming smokers and a similar approach is needed. For any policy to be effective, the complex relationship between etiology of obesity, obesity advocacy, and marketing must be rewired. Marketing can play a key role in changing consumer preferences. This can include health conscious television, radio and internet advertising. No amount of advertising and consumer education would be useful unless we lower the price of healthy foods so low income residents can afford to buy them. The school environment needs to change as eating habits and choices developed in school are going to last a lifetime.

Thomas Farley, the health commissioner in New York City, reported a 5.5 percent decline in the number of obese schoolchildren from 2007 to 2011. Although this number is small, some argue that it is an indication that the obesity epidemic, one of the nation's most intractable health problems, may actually has a reversing course (Tavernise, 2012). Some experts note that the current declines, concentrated among higher income, mostly white populations, are still not benefiting many minorities' children. For example, when in New York City, they measured children in kindergarten through eighth grade from 2007 to 2011, the number of white children who were obese dropped by 12.5 percent, while the number of obese black children dropped by 1.9 percent (Tavernise, 2012). Though obesity is now part of the national conversation with aggressive advertising campaign in major cities in the Unites States, many scientists doubts that anti-obesity programs actually work. Researchers say that it will take a broad set of policies applied systematically to effectively reverse the trend (McGuire, 2012).

None of this can be accomplished without a policy intervention from the government with support from public interest groups. Stemming the obesity epidemic cannot be separated from stemming the tide of poverty and income inequality gap. There is growing evidence that obesity in America is largely an economic issue.

The main message is that obesity is established very early in life, and that it basically tracks through adolescence to adulthood. Therefore, improving meals in schools, teaching nutrition and the importance of physical activity, and getting rid of soda machines could help to reduce obesity. Is the obesity issue related to rising fast-food outlets and vending machines and too much advertising or to falling minimum wage, income inequality gap and lack of health and family benefits? These issues need to be addressed through a concerted program of environmental and policy interventions.

Even if the link between inequality, poverty and health were clearly established and tested, the public health profession has no particular expertise in reducing inequality and solving broader problems of social injustice, it is the responsibility of policy makers to design better policy to combat income inequality gap and poverty. 


\section{ENDNOTES}

1. Definition of Obese is provided by US department of Health and Human Services

2. See http://www.irp.wisc.edu/gaqs/faq2.htm and https://www.census.gov/hhes/www/poverty/about/overview/measure.

3. See Pedroni $(1996,2000,2001)$

\section{REFERENCES}

Andreyeva, T., Long, M. W., \& Brownell, K. D. (2010). The impact of food prices on consumption: a systematic review of research on the price elasticity of demand for food. American Journal of Public Health, February, 216-222.

Bai, J. (2004). Estimating cross-section common stochastic trends in nonstationary panel data. Journal of Econometrics, 122(1), 137-183.

Banerjee, A. (1999). Panel data unit roots and cointegration: an overview. Oxford Bulletin of Economics and Statistics, 61(S1), 607-629.

Banerjee, A., Marcellino, M., \& Osbat, C. (2004). Some cautions on the use of panel methods for integrated series of macroeconomic data. The Econometrics Journal, 7(2), 322-340.

Barness, L. A., Opitz, J. M., \& Gilbert-Barness, E. (2007). Obesity: Genetic, Molecular, And Environmental Aspects. American Journal of Medical Genetics Part A, 143A (24), 3016-3034.

BBC (2013). BBC News. Retrieved June 10, 2013 from www.bbc.co.uk

Behan, D. F., \& Cox, S. H. (2010), "Obesity and its Relation to Mortality and Morbidity Costs", Society of Actuaries. Retrieved April 1, 2013, from the Society of Actuaries database.

Bezruchka, S. (2001). Societal hierarchy and the health Olympics. Canadian Medical Association Journal, 164(12), 1701-1703.

Blisard, N., Stewart, H., \& Jolliffe, D. (2004). "Low-Income Households' Expenditures on Fruits and Vegetables", Agricultural Economic Report, No. 833. Retrieved May 1, 2004, from http://www.ers.usda.gov/publications/aer-agricultural-economic-

report/aer833.aspx\#.Ud9Qq0Esnss

Braveman, P. (2006), "Health disparities and health equality: Concepts and measurement", Annual Review Public Health, 27:167-94, https://www.youtube.com/watch?v=yVhp71bSRJk, Retreived June 13, 2014.

Breitung, J. (1999). The local power of some unit root tests for panel data (No. 1999, 69). Humboldt University of Berlin, Interdisciplinary Research Project 373: Quantification and Simulation of Economic Processes.

Breitung, J. (2002). Nonparametric tests for unit roots and cointegration. Journal of Econometrics, 108(2), 343-363.

Brody, J. E. (n.d.). In Fight Against Obesity, Drink Sizes Matter. Health and Wellness. Retrieved October 1, 2012, from http://well.blogs.nytimes.com/2012/10/22/in-fight-against-obesity-drink-sizesmatter/

Brownell, K. D., \& Horgen, K. B. (2004). Food fight: the inside story of the food industry, America's obesity crisis, and what we can do about it. Chicago: Contemporary Books.

Campbell, J. Y., \& Perron, P. (1991). Pitfalls and opportunities: what macroeconomists should know about unit roots? NBER macroeconomics annual, 6, 141-201.

Centers for Disease Control and Prevention (2012). Childhood Obesity Facts, Retrieved May 2016, from https://www.cdc.gov/healthyschools/obesity/facts.htm

Centers for Disease Control and Prevention (n.d). Adult Obesity Facts. Retrieved October 13, 2012, from http://www.cdc.gov/obesity/data/trends.html

Chanjin, C., \& Myers, Jr., S. L. (1997). Do the Poor Pay More for Food? Journal of Consumer Affairs, 33(2), 276-296. 
Chou, S-Y, Grossman, M., \& Saffer, H. (2004). An Economic Analysis Of Adult Obesity: Results From The Behavioral Risk Factor Surveillance System. Journal of Health Economics, 23(3), 565-587.

Chou, S-Y., Rashad, Inas; and Grossman, M.(2008). "Fast-Food Advertising on Television and Its Influence on Childhood Obesity" Journal of Law and Economics, 51(4), 599-618.

Dalrymple, T. (2010, May 7). Our Big Problem. Wall Street Journal, p. A1.

Darmon, N., Ferguson, E. L., \& Briend, A. (2002). A Cost Constraint Alone Has Adverse Effects on Food Selection and Nutrient Density: An Analysis of Human Diets by Linear Programming. Journal of Nutrition, 132, 3764-3771.

Dazinger, S (2013), “The Mismeasure of Poverty", The New York Times, September 18, P. A21.

Dietz, W., \& Gortmaker, S. (1985). Do We Fatten Our Children at the TV Set? Obesity and Television viewing in Children and Adolescent. Pediatrics, 75, 807-812.

Drewnowski, A., \& Darmon, N. (2005). The Economics of Obesity: Dietary Energy Density and Energy Cost.American Society for Clinical Nutrition, 82 (1), 1.

Economic Research Service of the USDA (n.d.) Retrieved 17 July 2013, from http://www.ers.usda.gov/media/224301/err55.pdf

Engle, R. F., \& Granger, C. W. (1987). Co-integration and error correction: representation, estimation, and testing. Econometrica: Journal of the Econometric Society, 251-276.

Esterl, M. (2012, October 5). Soda Makers to Post Calories on Vending Machines. Wall Street Journal, p. B3.

Finkelstein, E. A, Christopher J. Ruhm, C. J \& Kosa, K.M (2015). Economic causes and consequences of obesity, Annual Review Public Health, 26: 239-57.

Finkelstein, E., Ian C. Fiebelkorn, and Guijing,W. (2003). National medical spending attributable to overweight and obesity: How much, and who's paying? Health Affairs published May 14, 2003 as a Web Exclusive.

Finkelstein, E., \& Zuckerman, L. (2008).The fattening of America: how the economy makes us fat, if it matters, and what to do about it. Hoboken, N.J.: Wiley.

Finkelstein E. A., Strombotne, K.L.\& Popkin, B.M. (2010) The costs of obesity and implications for policymakers. Choices, Retrieved from http://www.choicesmagazine.org/magazine/article.php?article $=136$

Flegal, K. M., Caroll, M. D., Ogden, C. L., \& Curtin, L. R. (2010). Prevalence and trends in obesity among US adults, 1999-2008. Journal of the American Medical Association, 303(3), 235-241. Retrieved January 1, 2011, from http://jama.jamanetwork.com/article.aspx?articleid=185235

Fletcher, J., Frisvold, D. E., \& Tefft, N. (2010). Can Soft Drink Taxes Reduce Population Weight?. Contemporary Economic Policy, 28(January), 23-35.

Frazao, E., \& Allshouse, J. (2003). Strategies for Intervention: Commentary and Debate. Journal of Nutrition, 133(3). $\quad$ Retrieved January $1, \quad 2011, \quad$ from http://jn.nutrition.org/content/133/3/844S.short

French, S. A., Story, M., \& Levine, R. (1997). Pricing Strategy To Promote Fruit And Vegetable Purchase In High School Cafeterias. Journal of the American Dietetic Association, 97(9), 10081010.

Glanz, K., Basil, M., Maibach, E., Golberg, J., \& Snyder, D. (1998). Why Americans Eat What They Do Taste, Nutrition, Cost, Convenience, And Weight Control Concerns As Influences On Food Consumption. Journal of the American Dietetic Association, 98(10), 1118-1126. Retrieved January 1, 2011, from the PubMed.org database.

Hammond, R., \& Levine, R. (2010). The economic impact of obesity in the United States. Diabetes, Metabolic Syndrome and Obesity: Targets and Therapy, 3, 285-295. Retrieved January 1, 2011, from http://www.ncbi.nlm.nih.gov/pmc/articles/PMC3047996/

Henderson, L. J. (2007). Obesity, Poverty and Diversity: Theoretical and Strategic Challenges. Obesity, business, and public policy (pp. 57-75). Cheltenham, UK: Edward Elgar.

Heggeness, Misty L. and Charles Hokayem (2013), "Life on the Edge: Living Near Poverty in the United States, 1966-2011," U.S. Census Bureau SEHSD Working Paper 2013-02, Washington, DC. 
Hojjat, T. A. \& Hojjat, R. (2017).The Economics of Obesity: Poverty, Income Inequality and Health, SpringerBrief in Public Health.

Huntrods, D., \& Koundinya, V. (2012, May 1). Sugarcane Profile, Agricultural Marketing Resource Center. Retrieved January 1, 2013, from http://www.agmrc.org/commodities_products/grains_oilseeds/sugarcane-profile/

Hyman, M. (2006). UltraMetabolism: the simple plan for automatic weight loss. New York: Scribner.

Im, K. S., Pesaran, M. H., \& Shin, Y. (2003). Testing for unit roots in heterogeneous panels. Journal of Econometrics, 115(1), 53-74.

Jenkins, H. W. (2013, January 29). "Coke and the Calories Wars", The Wall Street Journal, p. A11.

Kawachi , I (2000), Is Inequality Bad for Our Health, Boston: Beacon Press

Kawachi, I., Kennedy, B. P., \& Wilkinson, R. G. (1999). The society and population health reader, volume I: income inequality and health. New York: New Press

Kim, J.-S., \& Frees, E. W. (2007). Multilevel modeling with correlated effects. Psychometrika, 72, 505533.

Lakdawalla, D., \& Philipson, T. (2002). http://www.nber.org/papers/w8946.national bureau of economics, Working Paper(8946). Retrieved January 1, 2011 from http://www.nber.org/papers/w8946

Lakdawalla, D., Philipson, T., \& Bhattacharya, J. (2005). Welfare-enhancing technological change and the growth of obesity. The American Economic Review, 95(2), 253-257.

Lakdawalla, D., \& Philipson, T. (2009). The Growth Of Obesity And Technological Change. Economics \& Human Biology, 7(3), 283-293.

Landro, L. (2012, September 24), "School Nurses' New Role in Children's Health", The Wall Street Journal, p. D3.

Levin, A., Lin, C. F., \& Chu, C. S. J. (2002). Unit root tests in panel data: asymptotic and finite-sample properties. Journal of Econometrics, 108(1), 1-24.

Lynch, J.W \& Kaplan G.A (1997), "Understanding How Inequality in the Distribution of Income Affects Health", Journal of Health Psychology, London, Thousand Oaks and New Delh: Sage Publications.

Ludwig, D. S. (2007). Childhood Obesity - The Shape Of Things To Come. New England Journal of Medicine, 357(23), 2325-2327. Retrieved October 28, 2012, from http://dx.doi.org/10.1056/NEJMp0706538

Mantovani, Richard E., Lynn Daft, Theodore F. Macaluso, James Welsh, and Katherine Hoffman (1997), "Authorized Food Retailer Characteristics Study, Technical Report IV: Authorized Food Retailers' Characteristics and Access Study," research report, USDA, Food and Consumer Service, Office of Analysis and Evaluation.

Mark, N. C., \& Sul, D. (2003). Cointegration vector estimation by panel DOLS and long-run money demand. Oxford Bulletin of Economics and Statistics, 65(5), 655-680.

McCoskey, S., \& Kao, C. (1998). A residual-based test of the null of cointegration in panel data. Econometric Reviews, 17(1), 57-84.

McCrory, M. A., Fuss, P. J., Hays, N. P., Vinken, A. G., Greenberg, A. S., \& Roberts, S. B. (1999). Overeating in America: association between restaurant food consumption and body fatness in healthy adult men and women ages 19 to 80. US National Library of Medicine - National Institute of Health, 7(6), 564-571.

McGranahan, L., \& Schanzenbach, D. W. (2011). Who would be affected by soda taxes? Chicago Fed Letter, 284, 2-4.

McGuire, S. (2012) Accelerating progress in obesity prevention: solving the weight of the nation. Adv Nutr 3:708-709. doi:10.3945/ an.112.002733

Marmot, M. G., Stansfeld, S., Patel, C., North, F., Head, J., White, I. \& Smith, G. D. (1991). Health inequalities among British civil servants: the Whitehall II study. The Lancet, 337(8754), 13871393. 
Monteiro, C. A., Moura, E. C., Conde, W. L., \& Popkin, B. M. (2004). Socioeconomic status and obesity in adult populations of developing countries: a review. Bulletin of the World Health organization, 82(12), 940-946.

Morland, K., Wing, S., Roux, A. D., \& Poole, G. (2002). Neighborhood characteristics associated with the location of food stores and food service places. American Journal of Preventative Medicine, 22, 23-29.

Neel, J. V. (1962). Diabetes mellitus: a "thrifty" genotype rendered detrimental by "progress"? American Journal of Human Genetics, 14, 353-362.

Newey, W. K., \& West, K. D. (1994). Automatic lag selection in covariance matrix estimation. The Review of Economic Studies, 61(4), 631-653.

Ogden, C, Lamb, M. Carroll, M.D. Flegal K. M (2010), Obesity and Socioeconomic Status in Adults: United States, 2005-2008, Retrieved May 31, 2014 from http://www.cdc.gov/nchs/data/databriefs/db50.pdf,

Phillips, P. C. (1995). Fully modified least squares and vector autoregression. Econometrica: Journal of the Econometric Society, 1023-1078.

Pedroni, P. (1999). Critical values for cointegration tests in heterogeneous panels with multiple regressors. Oxford Bulletin of Economics and Statistics, 61(S1), 653-670.

Pedroni, P. (2001). Fully modified OLS for heterogeneous cointegrated panels. In Nonstationary panels, Panel Cointegration, and Dynamic Panels (pp. 93-130). Emerald Group Publishing Limited.

Pollan, M. (2006). The omnivore's dilemma: a natural history of four meals. New York: Penguin Press.

Powell, L. M., \& Chaloupka, F. J. (2009). Food prices and obesity: evidence and policy implications for taxes and subsidies. The Milbank Quarterly, 87(1), 229-257.

Providing Non-Caloric Beverages to Teens Can Help Them Avoid Excessive Weight Gain, Study Shows. (2012, September 21). Science Daily. Retrieved September 28, 2012 from www.sciencedaily.com/releases/2012/09/120921162305.htm

Quesenberry, C. P., Jr, Caan, B., and Jacobson, A. (1998). Obesity, health services use, and health care costs among members of a health maintenance organization. Archives of Internal Medicine, $158(5), 466-472$.

Rolls, B. J., Morris, E. L., \& Roe, L. S. (2002). Portion size of food affects energy intake in normalweight and overweight men and women. American Journal of Clinical Nutrition, 76(6), 12071213.

Rolls, B. J., Ello-Martin, J. A., \& Tohill, B. C. (2004). What can intervention studies tell us about the relationship between fruit and vegetable consumption and weight management? Nutrition Reviews, 62(1), 1-17.

Saikkonen, P. (1991). Asymptotically efficient estimation of cointegration regressions. Econometric Theory, 7(1), 1-21.

Satel, S. \& Marmor, T.R. (2001), "Does Inequality Make You Sick? The Weekly Standard

Sobal, J., \& Stunkard, A. J. (1989). Socioeconomic Status And Obesity: A Review Of The Literature.. Psychological Bulletin, 105(2), 260-275.

Sommers, A. R. (2009). Obesity among older Americans. Congressional Research Service, Retrieved January 1, 2011, from http://www.aging.senate.gov/crs/aging3.pdf

Stock, J. H., \& Watson, M. W. (1993). A simple estimator of cointegrating vectors in higher order integrated systems. Econometrica: Journal of the Econometric Society, 783-820.

Sturm, R., \& Datar, A. (2005). Body Mass Index In Elementary School Children, Metropolitan Area Food Prices And Food Outlet Density. Public Health, 119(12), 1059-1068.

Sturm, R. (2007). Increases In Morbid Obesity In The USA: 2000-2005. Public Health, 121(7), 492-496.

Stutzer, A. (2007). Limited Self-Control, Obesity and the Loss of Happiness. Social Science Research Network, Discussion Paper No. 2925, 10. Retrieved January 1, 2011 from http://papers.ssrn.com/sol3/papers.cfm?abstract_id=1001413

Subramanian, S. V., \& Kawachi, I. (2004). Income Inequality And Health: What Have We Learned So Far?.epidemiologic reviews, 26(1), 78-91. 
Tavernise, S. (2012, December 10). Obesity in Young Is Seen As Falling In Several Cities. New York Times, pp. A1-3.

Thompson, D., Edeslberg, J., Kinsey, K. L., \& Oster, G. (1998). Estimated economic costs of obesity to U.S. business. American Journal of Health Promotion, 13(2), 120-127.

Thompson, D., Brown, J. B., Nichols, G. A., Elmer, P. J., \& Oster, G. (2001). Body Mass Index And Future Healthcare Costs: A Retrospective Cohort Study. Obesity, 9(3), 210-218.

Tomer, J. (2011). What causes obesity? And why has it grown so much? Challenge, 54(4), 22.

Tomer, J. F. (2008). Intangible capital: its contribution to economic growth, well-being and rationality. Cheltenham, UK: Edward Elgar.

Urbain, J. P. (2004). Spurious regression in nonstationary panels with cross-member cointegration. mimeo.

Vara, V. (2012, August 12). Campaign Over Soda Tax Bubbles Up. The Wall Street Journal, p. A3.

Westerlund, J. (2005). Data dependent endogeneity correction in cointegrated panels. Oxford Bulletin of Economics and Statistics, 67(5), 691-705.

Wilkinson, R. (1996), Unhealthy Societies: The Afflictions of Inequality, London, New York: Routledge

Winterman, D. (2012). Child obesity: Why do parents let their kids get fat? BBC news magazine, Retrieved June 10, 2013 from http://www.bbc.co.uk/news/magazine-19661085

Zizza, C., Siega-Riz, A. M., \& Popkin, B. M. (2001). Significant Increase In Young Adults' Snacking Between 1977-1978 And 1994-1996 Represents A Cause For Concern! Preventive Medicine, 32(4), 303-310. 


\section{APPENDIX}

TABLE 1

WEIGHT RANGE

\begin{tabular}{|l|l|l|l|}
\hline Height & Weight Range & BMI & Considered \\
\hline $\mathbf{5}^{\prime} \mathbf{9}^{\prime \prime}$ & $124 \mathrm{lbs}$ or less & Below 18.5 & Underweight \\
\hline & $125 \mathrm{lbs}$ to $168 \mathrm{lbs}$ & 18.5 to 24.9 & Healthy weight \\
\hline & $169 \mathrm{lbs}$ to $202 \mathrm{lbs}$ & 25.0 to 29.9 & Overweight \\
\hline & $203 \mathrm{lbs}$ or more & 30 or higher & Obese \\
\hline
\end{tabular}

Source: National Center for Health Statistics, 2011

TABLE 2

HEALTH ISSUES AMONG ALL-SCHOOL-AGED CHILDREN IN U.S.

\begin{tabular}{|l|l|}
\hline Obese, overweight, $32 \%$ & Asthma, $10 \%$ \\
\hline Vision deficiencies, $24 \%$ & Food allergies, $5 \%$ \\
\hline Prescribed medication for more than 90 days, $13 \%$ & Seizure disorder, $5 \%$ \\
\hline Mental, emotional or behavioral problems, $10 \%$ & Hearing deficiencies, $5 \%$ \\
\hline $\begin{array}{l}\text { Illness or injury resulting in more than } 11 \text { missed school } \\
\text { days, } 6 \%\end{array}$ & $\begin{array}{l}\text { Attention Deficit Hyperactivity Disorder, } \\
5 \%\end{array}$ \\
\hline
\end{tabular}

Source: National Association of School Nurses and Wall Street journal, September 25, 2012, D3.

TABLE 2

FOOD AS A SHARE OF TOTAL EXPENDITURES, DEVELOPING AND ADVANCED COUNTRIES, 2011

\begin{tabular}{|l|l|l|l|}
\hline Developing Country & $\begin{array}{l}\text { Food as a percentage } \\
\text { of total expenditures }\end{array}$ & $\begin{array}{l}\text { Advanced } \\
\text { Country }\end{array}$ & $\begin{array}{l}\text { Food as a percentage } \\
\text { of total expenditures }\end{array}$ \\
\hline China & $32.8 \%$ & Austria & $11.0 \%$ \\
\hline Guatemala & 35.5 & Denmark & 11.5 \\
\hline India & 35.4 & Finland & 11.19 \\
\hline Indonesia & 43.0 & France & 13.0 \\
\hline Jordan & 40.7 & Germany & 11.4 \\
\hline Kenya & 44.9 & Ireland & 7.2 \\
\hline Kazakhstan & 34.9 & Japan & 14.2 \\
\hline Nigeria & 39.9 & Norway & 12.9 \\
\hline Pakistan & 45.5 & Sweden & 11.5 \\
\hline Philippine & 38.7 & United Kingdom & 8.8 \\
\hline Ukraine & 42.1 & United States & 6.9 \\
\hline
\end{tabular}

Source: http://civileats.com/2011/03/29/mapping-global-food-spending-infographic/ 
TABLE 3

PERCENTAGE OF OBESE ADULTS BY HOUSEHOLD INCOME, 2007-2009

\begin{tabular}{|l|l|}
\hline \multicolumn{2}{|l|}{ Percentage of Obese Adults by Household Income, $2007-2009$} \\
\hline Less than $\$ 15,000$ & $35.3 \%$ \\
\hline$\$ 15,000$ to $\$ 24,999$ & $31.4 \%$ \\
\hline$\$ 25,000$ to $\$ 34,999$ & $29.6 \%$ \\
\hline$\$ 35,000$ to $\$ 49,999$ & $29.1 \%$ \\
\hline$\$ 50,000+$ & $24.5 \%$ \\
\hline
\end{tabular}

Source: "F As In Fat: How Obesity Threatens America's Future," Trust for America's Health, June 2010

TABLE 4

PERCENTAGE OF OBESE ADULTS BY EDUCATIONAL LEVEL, 2007-2009

\begin{tabular}{|l|l|}
\hline Percentage of Obese Adults by Educational Level, 2007-2009 \\
\hline Did not graduate high school & $33.6 \%$ \\
\hline Graduated high school & $30.3 \%$ \\
\hline Attended college or technical school & $29.6 \%$ \\
\hline Graduated college or technical school & $22.0 \%$ \\
\hline
\end{tabular}

Source: "F As In Fat: How Obesity Threatens America's Future," Trust for America's Health, June 2010.

TABLE 5

STATES WITH HIGHEST OBESITY RATES, 2013

[JANUARY-DECEMBER 2013, GALLUP-HEATHWAYS WELL-BEING INDEX]

\begin{tabular}{|l|l|}
\hline Ten States With Highest Obesity Rates & \% of Obese \\
\hline Mississippi & 35.4 \\
\hline West Virginia & 34.4 \\
\hline Delaware & 34.3 \\
\hline Louisiana & 32.7 \\
\hline Arkansas & 32.3 \\
\hline South Carolina & 31.4 \\
\hline Tennessee & 31.3 \\
\hline Ohio & 30.9 \\
\hline Kentucky & 30.6 \\
\hline Oklahoma & 30.5 \\
\hline
\end{tabular}

Source: http://www.gallup.com/poll/161717/boulder-remains-least-obese-metro-area.aspx 
TABLE 6

STATES WITH LOWEST OBESITY RATES, 2013

[JANUARY-DECEMBER 2013, GALLUP-HEATHWAYS WELL-BEING INDEX]

\begin{tabular}{|l|l|}
\hline Ten States With Lowest Obesity Rates & \% of Obese \\
\hline Montana & 19.6 \\
\hline Colorado & 20.4 \\
\hline Nevada & 21.1 \\
\hline Minnesota & 22.0 \\
\hline Massachusetts & 22.2 \\
\hline Connecticut & 23.2 \\
\hline New Mexico & 23.5 \\
\hline California & 23.6 \\
\hline Hawaii & 23.7 \\
\hline New York & 24.0 \\
\hline
\end{tabular}

Source: http://www.gallup.com/poll/161717/boulder-remains-least-obese-metro-area.aspx

TABLE 7

PANEL UNIT ROOT TEST

\begin{tabular}{|l|l|l|l|l|l|}
\hline \multicolumn{1}{|c|}{ Variable } & \multicolumn{1}{c|}{ LLC } & & Breitung & IPS & Breitung \\
\hline & None & Intercept & Trend & Trend & intercept \\
\hline 1_obese & 11.28 & $-8.06^{* * *}$ & $-12.19^{* * *}$ & $-3.30^{* * *}$ & -1.59 \\
\hline 1_gini & $-8.39 * * *$ & 1.90 & 5.92 & 0.38 & -1.06 \\
\hline 1_poverty & 0.64 & $-6.11^{* * *}$ & $-9.26^{* * *}$ & $-3.87^{* * *}$ & $-2.77^{* * *}$ \\
\hline
\end{tabular}

N.B: LLC=Levin, Lin, Chu (2002), IPS=Im, Pesaran, Shin (2003). The other statistics are described in detail in Breitung (2000. The statistics are asymptotically distributed as standard normal with a left hand side rejection area. $A{ }^{* * *}$ indicates the rejection of the null hypothesis of nonstationarity (LLC, Breitung, IPS) at $1 \%$ level of significance.

TABLE 8

PANEL UNIT ROOT TEST ( 1ST DIFFERENCE)

\begin{tabular}{|l|l|l|l|l|l|l|}
\hline Variable & \multicolumn{4}{|l}{ LLC } & Breitung & IPS \\
\hline & None & intercept & Trend & Trend & intercept & Trend \\
\hline 1_obese & $-29.85^{* * *}$ & $-36.73^{* * *}$ & $-40.07 * * *$ & $-19.14^{* * *}$ & $-5.97^{* * *}$ & $-6.38^{* * *}$ \\
\hline 1_gini & $-22.52^{* * *}$ & $-12.99^{* * *}$ & $-10.96^{* * *}$ & $-3.60^{* * *}$ & $-3.38^{* * *}$ & $-3.38^{* * *}$ \\
\hline 1_poverty & $-35.98^{* * *}$ & $-30.81^{* * *}$ & $-28.47^{* * *}$ & $-13.80^{* * *}$ & $-5.13^{* * *}$ & $-5.26^{* * *}$ \\
\hline
\end{tabular}

N.B: LLC=Levin, Lin, Chu (2002), IPS=Im, Pesaran, Shin (2003). The other statistics are described in detail in Breitung (2000. The statistics are asymptotically distributed as standard normal with a left hand side rejection area. $A^{* * *}$ indicates the rejection of the null hypothesis of nonstationarity (LLC, Breitung, IPS) at 1\% level of significance 
TABLE 9

PANEL COINTEGRATION TEST

\begin{tabular}{|l|l|l|l|l|l|l|}
\hline & \multicolumn{2}{|l|}{ Panel statistics } & Group statistics & Intercept & $\begin{array}{l}\text { Intercept and } \\
\text { Trend }\end{array}$ \\
\hline & None & Intercept & $\begin{array}{l}\text { Intercept } \\
\text { and Trend }\end{array}$ & None & & \\
\hline $\begin{array}{l}\text { Variance } \\
\text { ratio }\end{array}$ & -3.078 & -3.342 & $8.697^{* * *}$ & & & \\
\hline Rho statistics & -0.953 & 2.661 & $-2.383^{* * *}$ & 1.627 & 5.019 & 0.770 \\
\hline PP statistics & $-5.206^{* * *}$ & 0.272 & $-13.845^{* * *}$ & $-6.641^{* * *}$ & -0.358 & $-16.985^{* * *}$ \\
\hline $\begin{array}{l}\text { ADF } \\
\text { statistics }\end{array}$ & $-4.013^{* * *}$ & -0.629 & $-5.809^{* * *}$ & $-6.372^{* * *}$ & -0.727 & $-5.802^{* * *}$ \\
\hline
\end{tabular}

N.B: Statistics are asymptotically distributed as standard normal. The Pedroni statistics are described in detail in Pedroni (1999). The variance ratio test is right-sided, while the other Pedroni tests are left-sided

TABLE 10

\section{PANEL COINTEGRATION TEST}

Null Hypothesis: No cointegration

Trend assumption: No deterministic trend

User-specified lag length: 1

Newey-West automatic bandwidth selection and Bartlett kernel

\begin{tabular}{|l|l|l|}
\hline & t-Statistic & Prob. \\
\hline ADF & $-6.006^{* * *}$ & 0.000 \\
\hline Residual variance & 0.008 & \\
\hline HAC variance & 0.008 & \\
\hline
\end{tabular}

N.B: The LM test from Kao and McCoskey (1998) is right-sided and carried out using either FMOLS or DOLS residuals. $A^{* * *}$ indicates the rejection of the null hypothesis of no cointegration (Pedroni) or no cointegration (Kao and McCoskey) at least on the 0.05 level of significance.

\section{TABLE 11 \\ COINTEGRATION REGRESSION (FMOLS)}

\begin{tabular}{|c|c|c|c|c|}
\hline \multicolumn{5}{|c|}{ Dependent Variable: 1 obese } \\
\hline \multicolumn{5}{|c|}{ Method: Panel Fully Modified Least Squares (FMOLS) } \\
\hline \multicolumn{5}{|c|}{ Panel method: Pooled estimation } \\
\hline \multicolumn{5}{|c|}{ Cointegrating equation deterministics: $\mathrm{C}$} \\
\hline \multicolumn{5}{|c|}{ Coefficient covariance computed using default method } \\
\hline \multicolumn{5}{|c|}{ Long-run covariance estimates (Bartlett kernel, Newey-West fixed bandwidth) } \\
\hline Variable & Coefficient & Std. Error & t-Statistic & Prob. \\
\hline 1_gini & 3.009 & 0.210 & 14.265 & 0.000 \\
\hline 1_poverty & 0.172 & 0.059 & 2.886 & 0.004 \\
\hline R-squared & 0.479 & \multicolumn{2}{|c|}{ Mean dependent var } & 3.119 \\
\hline Adjusted R-squared & 0.445 & \multicolumn{2}{|c|}{ S.D. dependent var } & 0.219 \\
\hline S.E. of regression & 0.163 & \multicolumn{2}{|c|}{ Sum squared resid } & 18.037 \\
\hline Durbin-Watson stat & 0.519 & \multicolumn{2}{|c|}{ Long-run variance } & 0.046 \\
\hline
\end{tabular}

N.B: Panel method is pooled estimation. The Cointegration equation is deterministic. We use Bartlett kernel lag and Newey-West fixed standard error of residuals. 


\section{TABLE 12 \\ COINTEGRATING REGRESSION (DOLS)}

\begin{tabular}{|c|c|c|c|c|}
\hline \multicolumn{5}{|c|}{ Dependent Variable: 1 obese } \\
\hline \multicolumn{5}{|c|}{ Method: Panel Dynamic Least Squares (DOLS) } \\
\hline \multicolumn{5}{|c|}{ Panel method: Pooled estimation } \\
\hline \multicolumn{5}{|c|}{ Cointegrating equation deterministics: $\mathrm{C}$} \\
\hline \multicolumn{5}{|c|}{ Fixed leads and lags specification (lead $=1, \operatorname{lag}=1)$} \\
\hline \multicolumn{5}{|c|}{ Coefficient covariance computed using default method } \\
\hline \multicolumn{5}{|c|}{ Long-run variance (Bartlett kernel, Newey-West fixed bandwidth) used for coefficient covariances } \\
\hline Variable & Coefficient & Std. Error & t-Statistic & Prob. \\
\hline 1_gini & 3.061 & 0.226 & 13.525 & 0.000 \\
\hline 1 poverty & 0.124 & 0.075 & 1.646 & 0.100 \\
\hline R-squared & 0.873 & \multicolumn{2}{|c|}{ Mean dependent var } & 3.098 \\
\hline Adjusted R-squared & 0.771 & \multicolumn{2}{|c|}{ S.D. dependent var } & 0.233 \\
\hline S.E. of regression & 0.111 & \multicolumn{2}{|c|}{ Sum squared resid } & 5.257 \\
\hline Long-run variance & 0.013 & & & \\
\hline
\end{tabular}

N.B: Panel method is pooled estimation. The Cointegration equation is deterministic. We use Bartlett kernel lag and Newey-West fixed standard error of residuals.

TABLE 13

\section{MULTI LEVEL ANALYSIS OF OBESITY, INCOME INEQUALITY AND POVERTY (RANDOM INTERCEPT CASE)}

\begin{tabular}{|c|c|c|c|}
\hline \multicolumn{4}{|c|}{ Dependent variable: $l$ obese } \\
\hline Variable & Model1 & Model2 & Model3 \\
\hline Constant & $\begin{array}{l}3.096 * * * \\
(0.000)\end{array}$ & $\begin{array}{l}2.457 * * * \\
(0.000)\end{array}$ & $\begin{array}{l}4.093 * * * \\
(0,000)\end{array}$ \\
\hline l_poverty & & $\begin{array}{l}0.257 * * * \\
(0.000)\end{array}$ & $\begin{array}{l}0.1404 * * * \\
(0.000)\end{array}$ \\
\hline l_gini & & & $\begin{array}{l}2.540 * * * \\
(0.000)\end{array}$ \\
\hline $\begin{array}{l}\text { St. Deviation } \\
\text { (constant) }\end{array}$ & $\begin{array}{l}0.096 \\
{[0.012]}\end{array}$ & $\begin{array}{l}0.085 \\
{[0.011]}\end{array}$ & $\begin{array}{l}0.162 \\
{[0.017]}\end{array}$ \\
\hline $\begin{array}{l}\text { St. Deviation } \\
\text { (residuals) }\end{array}$ & $\begin{array}{l}0.208 \\
{[0.005]}\end{array}$ & $\begin{array}{l}0.204 \\
{[0.004]}\end{array}$ & $\begin{array}{l}0.168 \\
{[0.004]}\end{array}$ \\
\hline Number of obs. & 896 & 896 & 896 \\
\hline Number of groups & 50 & 50 & 50 \\
\hline LR test $\left(\chi^{2}\right)$ & $\begin{array}{l}95.12 * * * \\
(0.000)\end{array}$ & $\begin{array}{l}71.69 * * * \\
(0.000)\end{array}$ & $\begin{array}{l}291.87 * * * \\
(0.000)\end{array}$ \\
\hline
\end{tabular}

$N . B:{ }^{*},{ }^{* *}$ and ${ }^{* * *}$ represent $10 \%, 5 \%$ and $1 \%$ level of significance respectively. The figures in parenthesis are $p$ values. The figures in square brackets are standard errors of corresponding estimates. The null hypothesis of $L R$ test is that there is no significant difference between the two models. 
FIGURE 1

LORENZ DIAGRAM

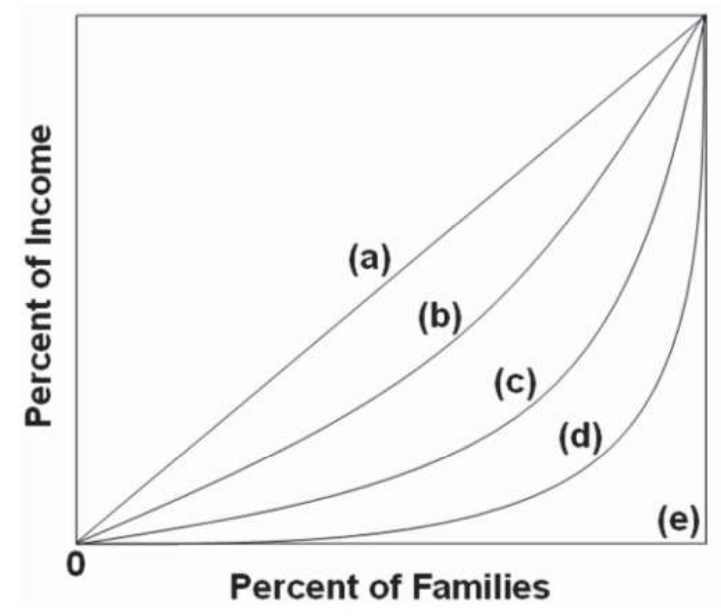

Journal of Applied Business and Economics Vol. 20(3) 2018 